\title{
Cohesive crack model for mixed mode fracture of brick masonry
}

\author{
E. Reyes · M. J. Casati · J. C. Gálvez
}

\begin{abstract}
This paper presents a numerical procedure for mixed mode fracture of brickwork masonry. The model is an extension of the cohesive model prepared by the authors for concrete, and takes into account the anisotropy of the material. After the crack path is obtained, an interface finite element (using the cohesive fracture model) is incorporated into the trajectory. Such a model is then implemented into a commercial code by means of a user subroutine, consequently being contrasted with experimental results. Fracture properties of masonry are independently measured for two directions on the composed masonry, and then input in the numerical model. This numerical procedure accurately predicts the experimental mixed mode fracture records for different orientations of the brick layers and two homothetic sizes on masonry panels.
\end{abstract}

Keywords Masonry $\cdot$ Mixed mode $\cdot$ Fracture $\cdot$ Experimental mechanics $\cdot$ Modelling

\section{Introduction}

Masonry is an ancient building material, with masonry structures constituting a large portion of the existing buildings around the world. Nowadays, brickwork masonry is profusely used for façades and internal walls in buildings with a concrete structure. A frequent problem of brickwork masonry structural elements and walls is cracking, associated with differential 
settlements and/or excessive deflections of slabs throughout the life of the structure (Steward and Lawrence 2002; Grimm 1998). Cracking of masonry is caused by the fragility and low capacity of the masonry, when accompanying structural elements such as floors, beams or foundations, in their movements. This problem is usually one of fracturing, where the wall is cracked under mixed mode fracture under quasi-static loading.

Until now, the study of brick masonry failure has been focussed on compression (Naraine and Sinha 1992; Alshebani and Sinha 1999; Khalaf et al. 1994; Naraine and Sinha 1991; Riddington and Naom 1994), compression/shear failure mechanisms (Lourenço 1996; Lourenço et al. 1998; Bernardini et al. 1998; Anthoine 1995; Mojsilovic and Marti 1997; Jukes and Riddintong 2001; Bosiljkov et al. 1998, 2000; Page 1978; Abdou et al. 2006; Molnar 2002) and out of plane bending (Abdoud et al. 1996; El-Metwally et al. 1991; van der Pluijm 1999). A certain amount of time has been given to studying tensile failure and in plane flexural/tensile mechanisms of brickwork masonry (mode I fracture) (Cormeau and Shrive 1996a,b; Carpinteri et al. 1997; Guinea et al. 2000; Alfaiate and Almeida 2000), and practically nothing (based on the fracture mechanics approach), to tensile/shear failure (Gálvez et al. 2000; Reyes et al. 2004; Reyes 2004; van der Pluijm 1997). Such a tensile/shear failure is known as mixed mode fracture (combination of the modes I and II).

Masonry may be considered a composite material made of brick units and mortar arranged forming layers, namely bed joints. The interface between brick and mortar is usually the weakest part of the masonry (Lourenço 1996; Page 1983). The large number of variables influencing the mechanical behaviour of masonry, e.g. material properties of brick and mortar, geometry of bricks, joints dimensions and arrangement, etc., make it a complex material, more so than concrete or mortar. This is the reason for fracture of brickwork masonry being an attractive challenge, given the long list of papers on the topic published over the past years corroborates, for many researchers.

Depending on the scale, the modelling of the masonry can be performed with different levels of abstraction, from a detailed representation of bricks, mortar and joints (Lourenço 1996; Rots 1991) to a global analysis as an isotropic or anisotropic continuum (Page 1981; Dhanasekar et al. 1985a,b; Papa and Nappi 1997; Lourenço and Rots 1993). The grade of refinement is directly related with the problem being analysed.

A micro-modelling approach (Guinea et al. 2000; Lourenço and Rots 1993; Zucchini and Lorenço 2002; Salerno et al. 2001) is useful for detailed analysis of the masonry failures on a small size structural element. Bricks, mortar and interfaces between mortar and brick are separately represented. In this case, that of micro defects in the mortar or bricks, stress concentration is induced by them, with interface debonding or other micro-defects possibly being adequately represented. The non-linear behaviour of the interfaces has been studied in detail by means of such models (Rahman and Anand 1994; Lourenço and Ramos 2004), as well as the individual fracture of mortar and bricks (Guinea et al. 2000). However, the failure analysis of large and geometrically complex structures using these models is usually unfeasible. The modelisation of the structure is highly time consuming with a powerful computer being required, in addition to some of the parameters of the material needed for computation being quite difficult to measure in real (especially ancient) buildings. Homogenisation techniques (Anthoine 1995; Zucchini and Lorenço 2002; Cecchi and Di Marco 2002; Uva and Salerno 2006; Milani et al. 2006; Papa 1996; Pietruszczak and Ushaksaraei 2003), are very useful in the numerical analysis of these problems and reduce the computational cost, though certain practical difficulties do remain.

A meso-modelling approach represents a complementary way to model the masonry fracture (Lourenço et al. 1998; Page 1978; Pietruszczak and Ushaksaraei 2003; Massart et al. 2005; Giambanco et al. 2001). Such an approach is promising for large masonry structures, in 
which detailed modelling of brick and mortar leads to an expensive and unfeasible analysis. This paper presents a meso-mechanical procedure for the analysis of mixed mode fracture of brick masonry based on the cohesive crack approach. The model does not make any distinction between masonry units (bricks), mortar and joints, averaging the effect of the composite material through the formulation of a fictitious continuous material. The material is assumed to be homogeneous and anisotropic. The model has been successful for mixed mode fracture of concrete and mortar (Gálvez et al. 2002a,b), which are considered homogenous and isotropic materials at meso-level approach. In this work the model is extended to anisotropic materials, with the approach being promising when failure is governed by the development of a single macro-crack in large structural brick masonry elements.

With this model as a framework, fracture properties of the entire masonry are independently determined for, at least, two main directions of masonry by specific tests performed on this material, then being input to numerical simulation, where masonry is treated as the only material. The result is an anisotropic cohesive fracture model, which can predict the behaviour the whole masonry without resort to any kind of fitting or tuning procedure.

To check the model, a series of mixed fracture tests were performed on small masonry panels under three point bending (TPB) with non-symmetric loading. As will be shown later, the model can accurately predict loads and displacement throughout the test records. Masonry panels with different orientations of the bed joints and two similar sizes (ratio 2) were tested.

This work is not intended to be a small-scale testing nor modelling of real masonry walls. With this paper, the authors seek to emphasise that with this new approach, based on the cohesive crack modelling applied to masonry, it is possible to analyse the mixed mode fracture behaviour of this complex material. It is acknowledged that further work must be carried out to extend this modelling to full-scale masonry structures.

Whereas the following section examines the numerical modelling, Sect. 3 studies the experimental programme. Numerical predictions of the mixed mode fracture tests are then presented and discussed in Sect. 4, with stress distribution along the crack path being presented in Sect. 5. Finally, the conclusions obtained from the model and the experiments are presented in Sect. 6.

\section{Numerical modelling of the mixed mode fracture}

As mentioned above, the meso-scale approach is adopted in this work. Such an approach does not make any distinction between masonry bricks, mortar and joints, averaging the effect of the composite material through the formulation of a fictitious continuous material. This material is homogeneous, anisotropic and shows cohesive behaviour under tensile cracking. The approach is suitable when the failure is governed by the development of a single macro-crack in a large masonry structural element.

The numerical modelling of the mixed mode (I/II) fracture process of masonry is based on the incorporation of the cohesive crack model into a finite element code. The two main stages of the process are the calculation of the crack path and the incorporation of the cohesive interface crack model into the crack path; these stages are two different computational steps.

\subsection{Overview of the cohesive crack model}

The failure analysis of masonry has been based predominantly on modelling techniques developed for concrete with one of the most promising non-linear fracture theories being the cohesive crack model. Such a model, named the fictitious crack model by 

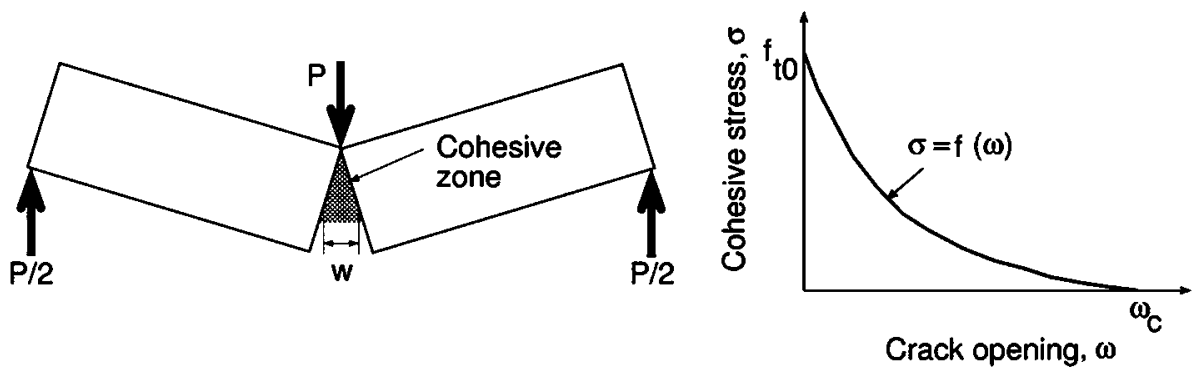

Fig. 1 Cohesive crack and softening function for mode I fracture of cohesive materials

Hillerborg et al. (1976), has been successful in the analysis of the fracture of concrete and concrete-like materials since its proposal (Hillerborg et al. 1976), as shown in Cendón et al. (2000), Bažant and Pfeiffer (1986), Carpinteri (1994). A detailed study of this model was published by Bažant and Planas (1998). Previous results reported by some authors suggest that this model can be satisfactorily applied to bricks (Bocca et al. 1989) and brickwork masonry (Guinea et al. 2000; Reyes et al. 2004; Reyes 2004).

The softening function, $\sigma=f(\omega)$, is the main ingredient of the cohesive crack model. This function is a material property and relates the stress acting across the crack faces, $\sigma$, to the corresponding crack opening, $\omega$ (see Fig. 1). In mode I opening, the stress transferred is normal to the crack faces.

Two properties of the softening curve are most important: the tensile strength, $f_{t 0}$, and the cohesive fracture energy, $G_{F}$. The tensile strength is the stress at which it is created and starts to open $\left(f(0)=f_{t 0}\right)$. The cohesive fracture energy, $G_{F}$, also called specific fracture energy, is the external energy required to create and fully break a unit surface area of a cohesive crack one which coincides with the area under the softening function.

The authors have successfully expanded on this model, originally developed for mode I fracture, to mixed mode fracture (I/II) of concrete (Gálvez et al. 2002a,b). In this paper the cohesive model for mixed mode fracture is extended to an anisotropic material, such as brickwork masonry. The model includes the dependence to the specific fracture energy, tensile strength and elastic modulus on the direction of the material (orientation of the bed joints).

\subsection{Numerical prediction of the crack trajectory}

Linear Elastic Fracture Mechanics (LEFM) has proved its worth in predicting the crack path, even for complex trajectories (Gálvez et al. 1998). This was tested in stable tests with brittle materials (Gálvez et al. 1996) and extended to quasi-brittle materials (Gálvez et al. 2002a,b; Gálvez et al. 1998). In this work, numerical computations use the Maximum Circumferential Stress Criterion (Erdogan and Sih 1963), which postulates that the crack grows perpendicularly to the greatest tension. Detailed information about this criterion can be found, for example, in Broek (1986). The LEFM finite element code FRANC2D (Wawryzynek and Ingraffea 1994) was used to calculate the crack paths.

\subsection{Cracking surface for mixed mode fracture}

Quasi-brittle materials, such as concrete or brickwork masonry, do not exhaust their tensile strength after a stress equal to the tensile strength is reached. Figure 2 shows a crack growing 


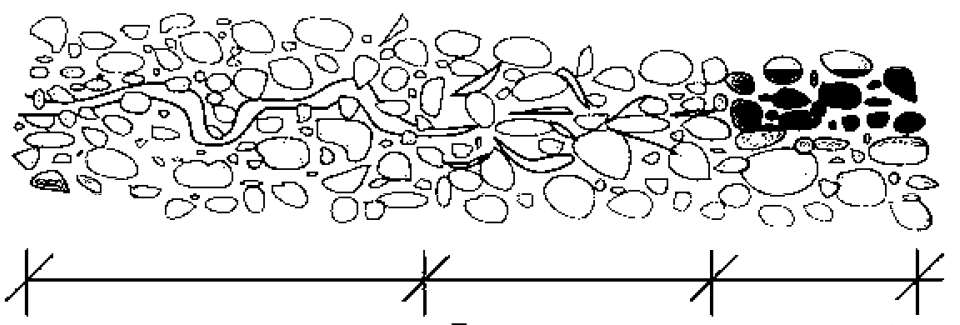

True crack

Fracture process Intact material zone (ZPF)
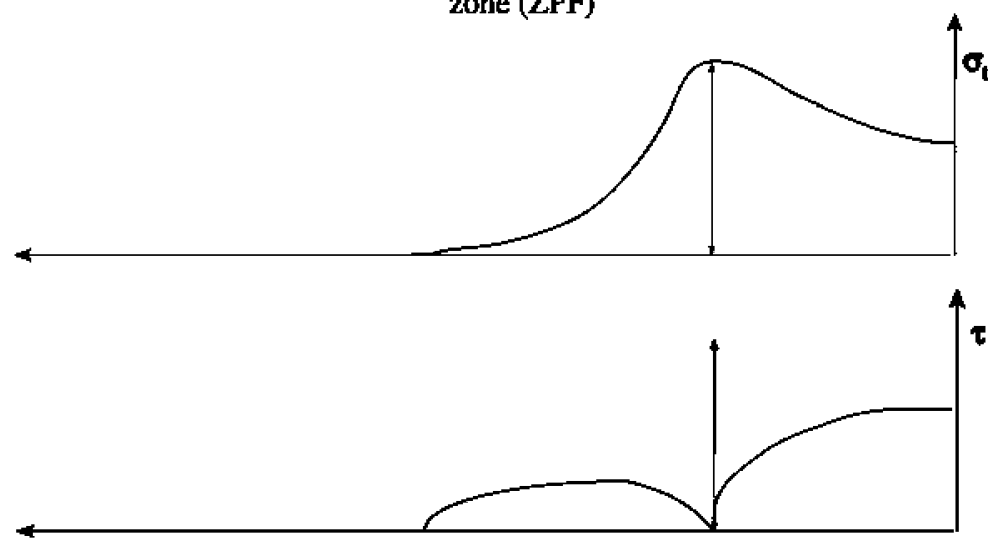

Fig. 2 Cracking process in concrete and profiles of tensile and tangential stresses

in these types of materials. From left to right three zones are distinguished: (1) the true crack, with no stress transmission through the interface, (2) the fracture process zone, where the material has been loaded up to its tensile strength and is partially broken, but with unbroken material bridges, through which is able to transmit stresses through the interface, and (3) the intact material, where the material has not been loaded up to its tensile strength. The cohesive crack model for mode I (Hillerborg et al. 1976) reproduces this behaviour through the softening curve that relates the normal stress, $\sigma$, transferred across the cohesive crack faces, as shown in Fig. 1.

In mixed mode (I and II) fracture, relative displacement between the upper and lower faces of the cohesive crack is vectorial in nature. We denote it as $\mathbf{u}$, with normal and shear components denoted as $u_{n}$ and $u_{t}$, i.e.,

$$
\mathbf{u}=u_{n} \vec{n}+u_{t} \vec{t}
$$

where $\vec{n}$ and $\vec{t}$ are the unit vectors respectively normal and tangential to the lower crack face.

Likewise, the stress transferred between the faces of the crack is also vectorial, and is characterised by the traction vector $\mathbf{t}$ acting on the lower face of the crack; with normal and tangential components denoted as $\sigma$ and $\tau$, i.e.,

$$
\mathbf{t}=\sigma \vec{n}+\tau \vec{t}
$$

In this work we adopt an elastoplastic formulation in which the crack displacement is split into its elastic and inelastic parts

$$
\mathbf{u}=\mathbf{u}^{e}+\mathbf{u}^{i}
$$


so that the traction vector is given by

$$
\mathbf{t}=\mathbf{K}_{e} \mathbf{u}^{e}
$$

where $\mathbf{K}_{e}$ is a second order elastic stiffness tensor. In the present work we assume that the shear and normal components are uncoupled. Therefore, the matrix of components of $\mathbf{K}_{e}$ in the basis $\{\vec{n}, \vec{i}\}$ is diagonal. We further assume that the normal and shear stiffness are identical, so that the matrix of components is actually

$$
\left[\mathbf{K}_{e}\right]=\mathbf{K}^{e}\left[\begin{array}{ll}
1 & 0 \\
0 & 1
\end{array}\right]
$$

Ideally, the initial stiffness of the cohesive crack would have to be infinite to reproduce the rigid-softening behaviour of a cohesive crack. For numerical computations, however, some large but finite value has to be adopted for $\mathrm{K}^{e}$. In this work we adopted values of $\mathbf{K}^{e}$ so that the normal or shear crack displacement at peak were around $0.001 \omega_{c}$, where $\omega_{c}$ is the crack displacement for which full softening has occurred (see Fig. 1).

For the inelastic behaviour, it is assumed that the inelastic crack opening can progress when the so-called cracking surface $F(t)=0$ is reached, similar to the yield surface in classical plasticity. For an isotropic material the following hyperbolic expression (Carol et al. 1997) has been assumed by the authors (Gálvez et al. 2000; Reyes et al. 2004; Reyes 2004):

$$
\mathbf{F}(\mathbf{t})=\tau^{2}-\tan \phi_{f}\left(f_{t}-\sigma\right)\left[2 c-\tan \phi_{f}\left(f_{t}+\sigma\right)\right]
$$

where $\phi_{f}, c$, and $f_{t}$ are the instantaneous values of the friction angle, cohesion and tensile strength. Such values only depend on loading history. In the case of an anisotropic material, they also depend on the direction that the crack forms with the main directions of the material. In this work we denote the angle between the greatest tensile stress and the bed joints as $\theta$. Then, the Eq. 6 is expressed as follows

$$
\mathbf{F}(\mathbf{t})=\tau^{2}-\tan \phi_{f}\left(f_{t}(\theta)-\sigma\right)\left[2 c(\theta)-\tan \phi_{f}\left(f_{t}(\theta)+\sigma\right)\right]
$$

where $\mathrm{c}(\theta)$ and $f_{t}(\theta)$ are the instantaneous values of the cohesion and tensile strength for $\theta$ angle. These parameters are assumed to depend on the loading history only through the effective inelastic crack displacement $u^{\text {ieff }}$, defined by the conditions

$$
\begin{gathered}
\dot{u}^{i e f f}=\left\|\dot{\mathbf{u}}^{i}\right\|=\left(\dot{u}_{n}^{2}+\dot{u}_{t}^{2}\right)^{0.5} \\
u^{i e f f}=\int \dot{u}^{i e f f} \mathrm{dt}
\end{gathered}
$$

In this work we assume that, for a given material, the friction angle $\phi_{\mathrm{f}}$ is constant, while the instantaneous tensile strength $f_{t}(\theta)$ and cohesion $\mathrm{c}(\theta)$ depend on $u^{\text {ieff }}$ bilinearly as depicted in Fig. 3. For an anisotropic material the values of $f_{t 0}$ and $\mathrm{c}_{0}$ depend on the $\theta$ angle. For the sake of simplicity we assume a linear variation of $f_{t 0}$ and $c_{0}$ in relation to $\theta$ angle, as is showed in Fig. 4.

The area enclosed between the softening curve for $f_{t}$ and the axes is the specific fracture energy $G_{F}^{I}$ for mode I (usually called fracture energy). The area defined by the softening curve for the cohesion and the axes also has dimensions of energy per unit area and was called the mode IIa specific fracture energy $G_{F}^{I I a}$ by Cervenka (1994), $G_{F}^{I I a}$ which is not directly measurable as no test can be devised in which the work of fracture is uniquely related to $G_{F}^{I I a}$. Usually, the $G_{F}^{I I a}$ is adopted by estimation of the ratio $\frac{G_{F}^{I I a}}{G_{F}^{I}}$. 
(a)

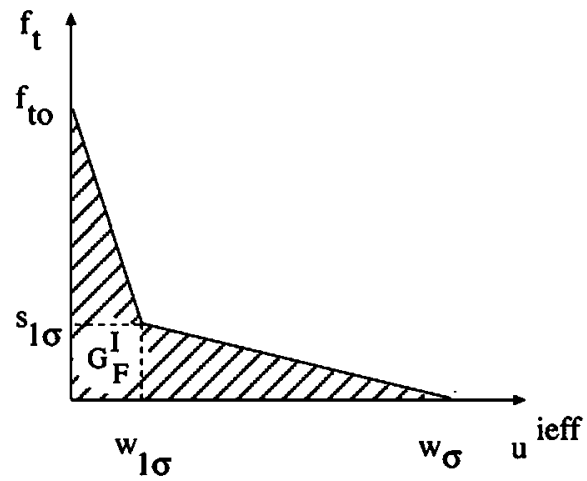

(b)

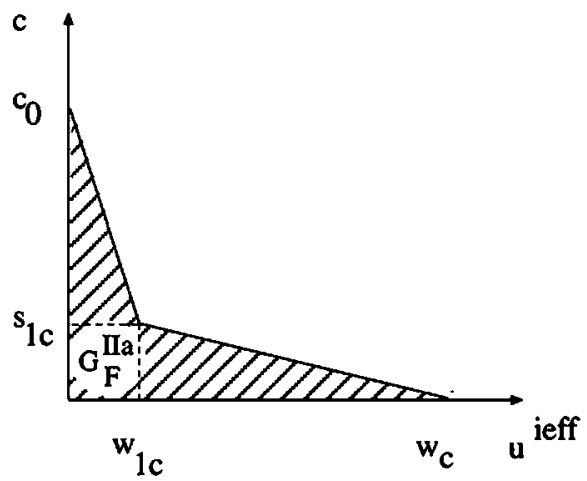

Fig. 3 Softening curves for brick masonry: (a) tensile strength, $f_{t}(\theta),(b)$ cohesion, $c(\theta)$

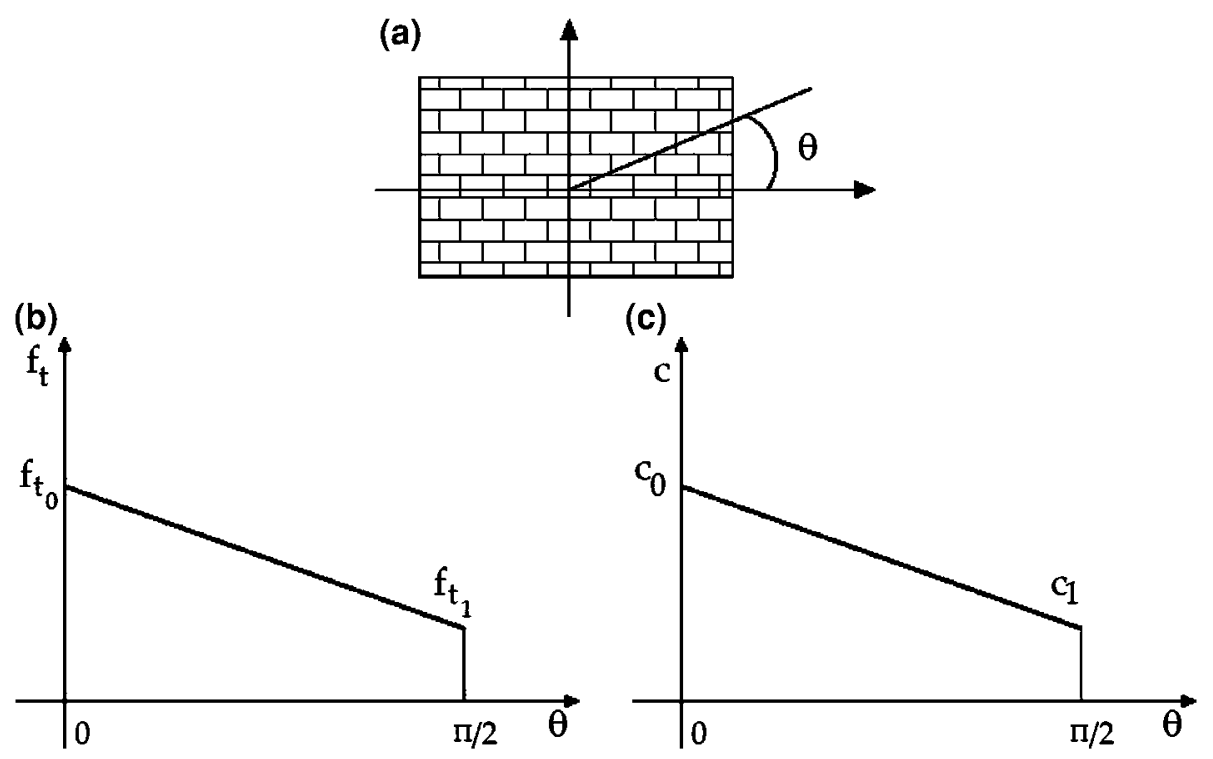

Fig. 4 Linear variation of the tensile strength and cohesion in relation to the $\theta$ angle: (a) angle between greatest tensile stress and bed joints, (b) tensile strength, and (c) cohesion

The bilinear softening curve for the tensile strength (see Fig. 3a) can be determined experimentally from mode I tests following the procedure devised by Bažant and Planas (1998) for concrete and mortar. For masonry, with a linear variation of $f_{t 0}$ in relation to $\theta$ angle, at least two directions of the bed joints are needed to be tested. At present, there is no way to measure directly the softening curve for the cohesion. Therefore, we assume that the shape of the two curves (tensile strength and cohesion) is the same and that the effective crack opening at which the tensile strength or cohesion becomes zero is the same (see Fig. 3. This leads to the following conditions for the characteristic points of the curve:

$$
\omega_{c}=\omega_{\sigma}, \omega_{1 c}=\omega_{1 \sigma}, c_{0}=f_{t 0} \frac{G_{F}^{I I a}}{G_{F}^{I}}, s_{1 c}=s_{1 \sigma} \frac{G_{F}^{I I a}}{G_{F}^{I}}
$$




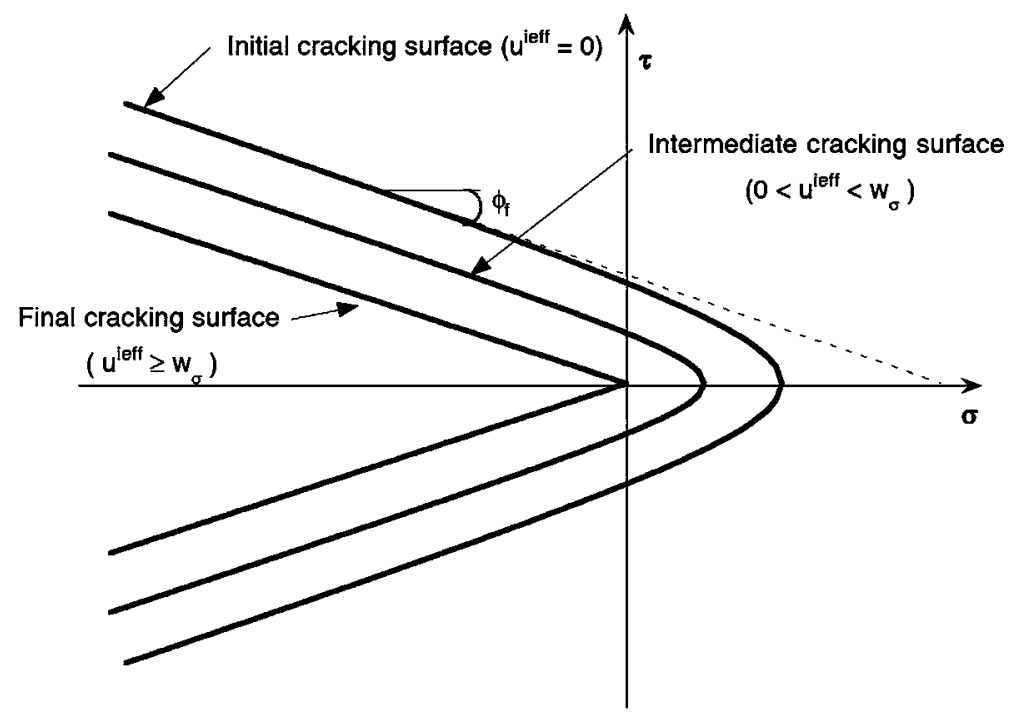

Fig. 5 Cracking surface and evolution

Figure 5 shows the cracking surface and its evolution under cracking conditions, based on the value of the parameter $u^{i e f f}$. It is worth noting that the cracking surfaces family depends on the $\theta$ angle. Note that for each state of damage the hyperbolic cracking surface has two branches and only the branch extending towards negative values of $\sigma$ is physically acceptable. Furthermore, it should also be noted that for fully damaged material (complete loss of tensile strength and cohesion), the cracking surface degenerates into a Coulomb friction surface with friction coefficient $\mu=\tan \phi_{f}$.

It is also worth noting that the ratio $\mathrm{c} / f_{t}=G_{F}^{I I a} / G_{F}^{I}$ cannot be selected arbitrarily. Indeed, for the equation $F(t)=0$ to be meaningful with $F(t)$ given by Eqs. 6 and 7 the factor in square brackets must be non-negative for any $\sigma \leq f_{\mathrm{t}}$ and thus we must have

$$
\frac{c}{f_{t}} \geq \tan \phi_{f} \text { and } \frac{G_{F}^{I l a}}{G_{F}^{I}} \geq \tan \phi_{f}
$$

Many softening curves have been developed to model the experimental fracture behaviour of quasibrittle materials in tension (Bažant and Planas 1998). The bilinear curves are accepted as reasonable approximations to the softening curve for quasibrittle materials, although there is no agreement about the precise location of the kink point.

For notched specimens of laboratory sizes (Guinea et al. 1994) and for unnotched specimens of all sizes (Planas et al. 1995), the peak load is completely determined by tensile strength and the initial part of the softening curve. Moreover, focussing on the size effect for bending specimens in a wide range of specimens and geometries (cracked and uncracked), the size effect curves are computed with similar accuracy for linear, bilinear and even trapezoidal softening functions (Guinea et al. 1997).

For such reasons, in this work the bilinear softening curve proposed by Hillerborg et al. (1976) and Petersson (1981) has been adopted, one that is widely used and includes only two parameters: tensile strength and cohesive fracture energy, which may be measured by means of standardised methods. Obviously, the proposed numerical procedure may be implemented 
with other approximations of the real softening curve (exponential and power law, among others).

Focussing on the mode II fracture parameters, a previous paper from Gálvez et al. (2002b) has shown that, under mixed mode fracture in notched specimens of a laboratory, significant mode II stresses build up only around the initial notch, but the crack propagation from that notch extends in the direction for which the stress state around the crack tip corresponds predominantly to mode I. Other papers (Jenq and Shah 1988; di Prisco et al. 2000) also postulate that under mixed mode fracture the mode II is negligible or non-existent. In this paper, for the sake of simplicity, the same softening parameter, $u^{\text {ieff }}$, has been adopted for the softening curves of both fracture modes, though independent softening curves may be implemented on the numerical procedure.

\subsection{Flow rule and dilatancy}

The evolution of the inelastic displacements in the fracture process zone is specified by means of the flow rule, given by

$$
\dot{\mathbf{u}}^{i}=\dot{\lambda} \frac{\partial Q(\mathbf{t})}{\partial \mathbf{t}}=\dot{\lambda} \mathbf{b}
$$

where $Q(\mathbf{t})$ is the plastic potential, b is the normal to the plastic potential surface and $\dot{\lambda}$ is a non-negative plastic multiplier.

In brickwork masonry, the tangential traction in a crack generates crack slip, at the same time as a crack opening due to the irregularities along the crack plane. This physical effect is named dilatancy. The dilatancy angle is defined

$$
\tan \phi_{d}=\frac{\dot{u}_{n}^{i}}{\dot{u}_{t}^{i}}
$$

where $\phi_{d}$ is the dilatancy angle, $\dot{u}_{n}^{i}$ and $\dot{u}_{t}^{i}$ are the incremental inelastic displacements in normal and tangential directions to the crack, respectively. $\phi_{d}$ coincide with the angle formed by the potential surface and the negative part of the $\sigma$ axis (see Fig. 6).

The dilatancy is also assumed to depend on the damage level through $u^{\text {ieff }}$. Following Carol et al. (1997), a linear curve has been adopted:

$$
\phi_{d}= \begin{cases}\phi_{d 0}\left(1-\frac{u^{i e f f}}{u_{c d}}\right) & \forall u^{i e f f}<u_{c d} \\ 0 & \forall u^{i e f f} \geq u_{c d}\end{cases}
$$

where $\phi_{d 0}$ is the initial value of the dilatancy angle and $u_{c d}$ is the critical inelastic crack displacement after which the crack ceases to exhibit the dilatancy effect.

When traction stress $\sigma$, is predominant over the tangential stress $\tau$, the direction normal to the plastic potential ( $Q=$ cte) is not defined. Consequently, in this case the return direction to the origin of stresses is adopted, which divides the stresses space into two parts, as is shown in Fig. 6. It should be pointed out that this is a non-associative plasticity approach, where normal directions to cracking surface and plastic potential are different.

\subsection{Integrating the rate equations}

The integration of the rate equations is based on the standard backward Euler scheme (see Reyes 2004 for details). The Eqs. 3 and 4 are differentiated and with Eq. $12 \dot{t}$ is obtained

$$
\dot{\mathbf{t}}=\mathbf{K}_{e}(\dot{\mathbf{u}}-\dot{\lambda} \mathbf{b}) \Rightarrow \Delta \mathbf{t}=\mathbf{K}_{e} \Delta \mathbf{u}-\mathbf{K}_{e} \Delta \lambda \mathbf{b}
$$




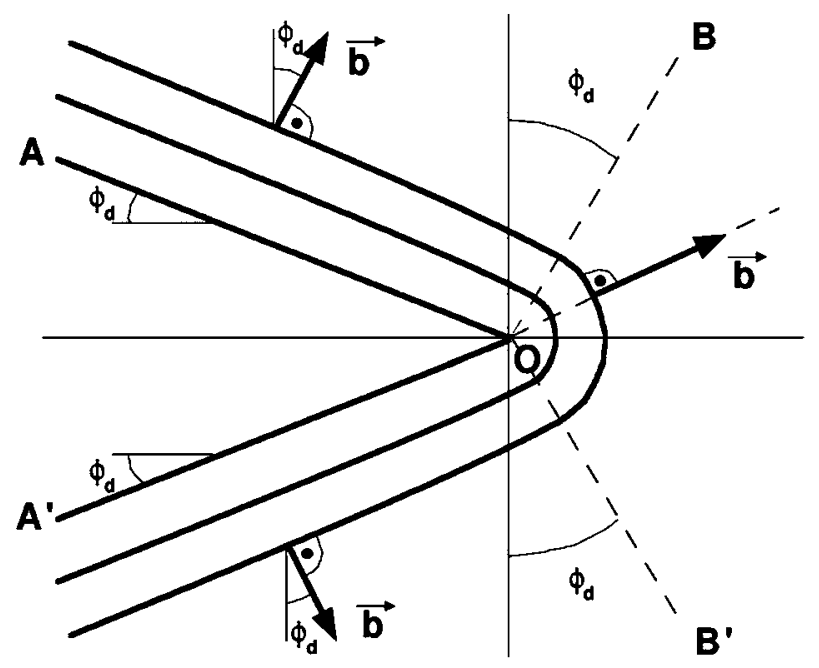

Fig. 6 Return direction to the cracking surface of the inelastic corrector

For a given state in the $n$th step, the traction vector, $t_{n}$, and the softening parameter, $u_{n}^{\text {ieff }}$, are known. Let us assume that in $\mathbf{n}$ step, the crack is growing, so the cracking surface equation is satisfied: $F\left(\mathbf{t}_{n}, u_{n}^{i e f f}\right)=0$.

An incremental relative displacement between crack faces is adopted, $\Delta \mathbf{u}_{n}=\mathbf{u}_{n+1}-\mathbf{u}_{n}$, and a the new traction state, $\mathbf{t}_{n+1}$, is calculated as follows

$$
\mathbf{t}_{e}=\mathbf{t}_{n}+\mathbf{K}_{e} \Delta \mathbf{u}
$$

where $\mathbf{t}_{e}$ is a new traction vector, obtained from an elastic predictor. If the crack is growing in the $n+1$ state the cracking surface equation should be satisfied, $F\left(\mathbf{t}_{n+1}, u_{n+1}^{i e f f}\right)=0$, and the traction vector, $\mathbf{t}_{n+1}$, is obtained from $\mathbf{t}_{e}$, adopting the inelastic corrector

$$
\mathbf{t}_{n+1}=\mathbf{t}_{e}-\Delta \lambda_{n} \mathbf{K}_{e} \mathbf{b}_{n}
$$

where $\Delta \lambda_{n} \mathbf{K}_{e} \mathbf{b}_{n}$ is the inelastic corrector, $\mathbf{K}_{e}$ is the elastic tensor and $\mathbf{K}_{e} \mathbf{b}_{n}$ is the return direction vector to the plastic potential $\left(Q=\right.$ cte). $\Delta \lambda_{n}$ is obtained since the cracking surface equation must be satisfied in the $n+1$ state:

$$
F\left(\mathbf{t}_{n+1}, u_{n}^{i e f f}\right)=F\left(\mathbf{t}_{e}-\Delta \lambda_{n} \mathbf{K}_{e} \mathbf{b}_{n}, u_{n}^{i e f f}\right)=0
$$

which expressed as a function of traction strength and cohesion gives:

$$
F\left(\mathbf{t}_{n+1}, c_{n}(\theta), f_{t n}(\theta)\right)=0
$$

where $c_{n}(\theta)$ and $f_{t_{n}}(\theta)$ are the cohesion and traction strength at $n$ state. Then, the parameters involved in the procedure are actualised:

$$
\begin{gathered}
\Delta u_{n}^{i e f f}=\left\|\Delta \mathbf{u}_{n}^{i}\right\|=\Delta \lambda_{n}\left\|\mathbf{b}_{n}\right\| \Rightarrow u_{n+1}^{i e f f}=u_{n}^{i e f f}+\Delta u_{n}^{i e f f} \\
f_{t_{n+1}}(\theta)=f_{t}\left(u_{n+1}^{i e f f}, \theta\right) ; c_{n+1}(\theta)=c\left(u_{n+1}^{i e f f}, \theta\right) ; \phi_{d_{n+1}}(\theta)=\phi_{d}\left(u_{n+1}^{i e f f}, \theta\right) ; \\
\mathbf{b}_{n+1}=\mathbf{b}\left(u_{n+1}^{i e f f}, \theta\right)
\end{gathered}
$$



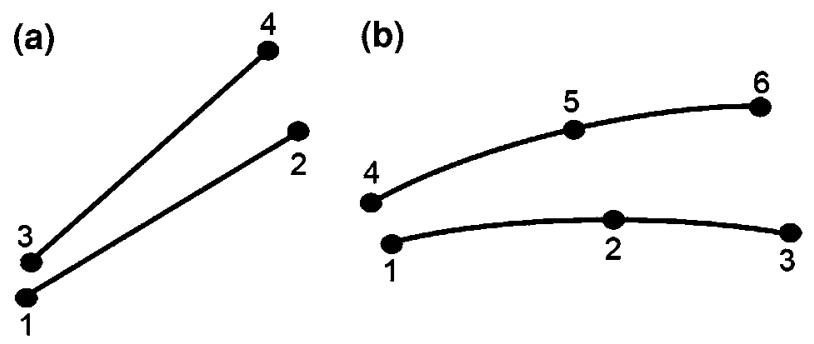

Fig. 7 Interface elements: (a) linear, (b) quadratic

It is worth noting that the traction strength, $f_{t}(\theta)$, the cohesion, $c(\theta)$, the return direction, $\mathbf{K}_{e} \mathbf{b}$, and the dilatancy angle, $\phi_{d}$, used in Eq. 18 corresponding to the $n$ state are not actualised to the $n+1$ state. This occurs because the value of the softening parameter, $u^{i e f f}$, obtained once the increment of the plastic multiplier, $\Delta \lambda$, is known. This leads to an iterative process that ends when the inelastic correction is below a prefixed value.

An interface element was developed to incorporate the model in the finite element code ABAQUS $^{(}$. Details regarding the finite element implementation are found in Reyes (2004), Gálvez et al. (2002a). Figure 7 shows a sketch of the interface element. An arc length algorithm was adopted for computational procedure and no special difficulties were found in achieving a convergent solution.

To simplify the computations, the bulk behaviour is commonly assumed to be linear-elastic and anisotropic, although this approximation can be relaxed if necessary.

\section{Experimental programme}

\subsection{Materials and specimens}

To check the model, a series of mixed fracture tests were performed on small masonry panels under TPB configuration with non-symmetric loading (Fig. 8). This test configuration has been successful for mixed mode fracture of concrete and mortar (Gálvez et al. 2002a; Gálvez et al. 1998).

This experimental programme is not intended to be a small scale modelling of real masonry walls. The aim of using scaled specimens is to capture the essentials of the mixed mode fracture of masonry while maintaining a reasonable experimental cost. This methodology, alternative to full-scale testing, has been widely used in masonry research since the mid-1950s, and is helpful in understanding the interaction between bricks and mortar joints (Guinea et al. 2000; Abboud and Hamid 1990). A scale factor of 1/4 was chosen, both to avoid difficulties in modelling the joint thickness, and have a representative number of bricks units in masonry specimens. Only geometric similitude requirements were considered, and the micro-mortar and the solid brick units used in this work were not intended to represent a real mortar, nor real brick units, as explained earlier.

Small-scale bricks of $48 \times 24 \times 10 \mathrm{~mm}^{3}$ were cut from commercial solid clay bricks. The cut was machined with a water-cooled low-speed diamond cutting disc. All the units were from the same batch to ensure homogeneous behaviour. Prismatic notched specimens of $240 \times 57.5 \times 37 \mathrm{~mm}^{3}$, with a notch to depth ratio of 0.5 , for fracture tests were sawn. See Reyes (2004) for further details. 


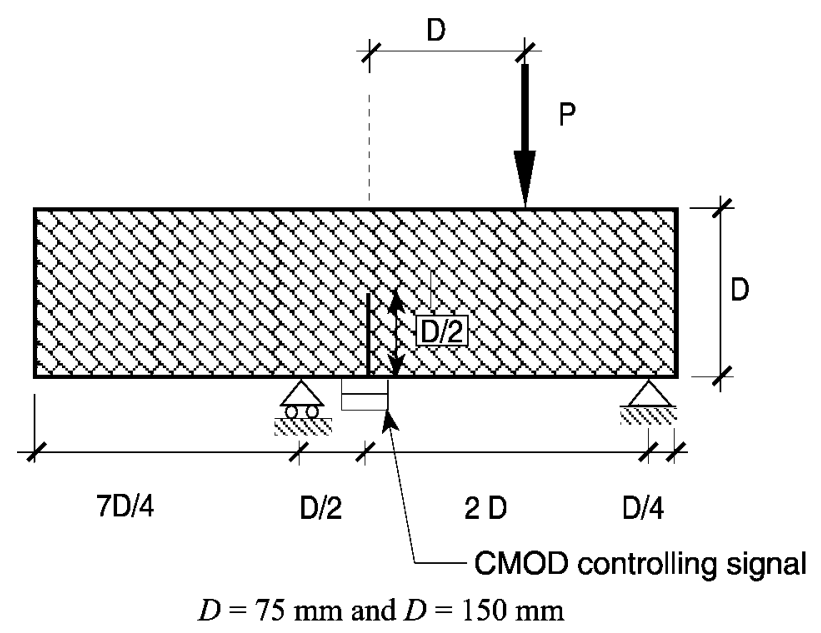

Fig. 8 Testing arrangement, geometry, dimensions, boundary conditions and instrumentation of the tested specimens under TPB configuration

The mortar used for masonry was both designed to meet similitude requirements and assure a workable mix. It was composed of Portland cement CEM I 42,5 N (ASTM Type I) and siliceous sand of $1 \mathrm{~mm}$ maximum size, compatible with the scaled-down thickness of the joints of $3 \mathrm{~mm}$. The grading of the sand complied with ASTM C-144 Standard. To improve the mechanical performance of the mortar, silica fume was added ( $13 \%$ of cement weight). Finally, superplasticiser was added to the mortar (3\% of the cement and fume silica weight) to make the filling of the joints easier.

Prismatic specimens of $337.5 \times 75 \times 26.5 \mathrm{~mm}^{3}$ were cast to characterise the mortar. Beams with a vertical joint between mortar and brick in the middle of the span were also cast to characterise the fracture and mechanical behaviour of the interface brick-mortar. Details may be also found in Reyes (2004).

Masonry panels were manufactured with the mortar and the small-scale units described above. Panels with three orientations of the bed joints $\left(0^{\circ}, 45^{\circ}\right.$ and $\left.90^{\circ}\right)$ and two similar sizes of $675 \times 150 \times 26.5$ and $337.5 \times 75 \times 26.5 \mathrm{~mm}^{3}$ were cast. The specimens were cast horizontally in prismatic ground steel moulds; small-scale bricks had been previously immersed in lime saturated water at $20^{\circ} \mathrm{C}$ for $24 \mathrm{~h}$. Then, the bricks were carefully fixed in the mould and the fresh mortar was poured over the matrix of bricks. The thickness of the joints was $3 \mathrm{~mm}$. The specimens remained in the moulds $48 \mathrm{~h}$, covered with saturated sacking at room temperature. They were later taken to a curing room and left there at $20^{\circ} \mathrm{C}$ and $98 \%$ relative humidity until testing. The panels were notched in the middle of the span, with a notch to depth ratio of 0.5 , before testing. In all cases the tip of the notch was inside a brick unit.

To obtain additional orientations of the joints in the panels, when the larger specimens were tested under TPB, small specimens $\left(337.5 \times 75 \times 26.5 \mathrm{~mm}^{3}\right)$ with the bed joints to $\pm 30^{\circ}$ and $\pm 60^{\circ}$ were obtained from the halves by cutting.

\subsection{Characterisation tests}

Characterisation fracture tests were performed on mortar, bricks and interface brick-mortar. Table 1 shows fracture energy and the tensile strength of them. Recommendations of RILEM 
Table 1 Mechanical properties of the constituent elements of brick masonry

\begin{tabular}{lcl}
\hline Element & $G_{F}(\mathrm{~N} / \mathrm{m})$ & $f_{t}(\mathrm{MPa})$ \\
\hline Brick & 107 & 7.6 \\
Mortar & 86 & 7.6 \\
Joint (brick-mortar) & 10 & - \\
\hline
\end{tabular}

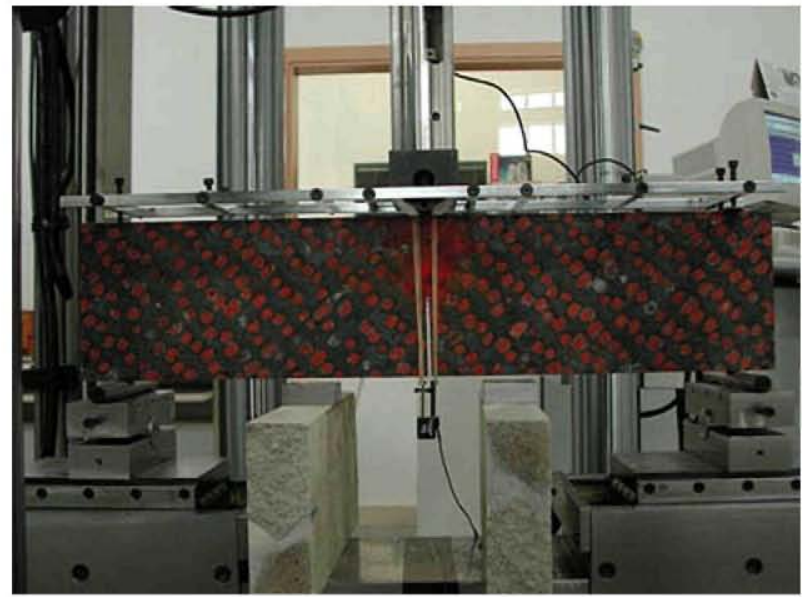

Fig. 9 Testing arrangement to measure the fracture properties of the brick masonry (bed joints at $45^{\circ}$ )

Table 2 Mechanical properties of brick masonry under mode I fracture

\begin{tabular}{llll}
\hline Orientation & $G_{F}(\mathrm{~N} / \mathrm{m})$ & $f_{t}\left(\mathrm{~N} / \mathrm{mm}^{2}\right)$ & $\mathrm{E}\left(\mathrm{kN} / \mathrm{mm}^{2}\right)$ \\
\hline Horizontal & 75 & 5.8 & 28 \\
$45^{\circ}$ & 54 & 4.1 & 22 \\
Vertical & 33 & 2.4 & 21 \\
\hline
\end{tabular}

50-FMC (RILEM50-FMC Committee Fracture Mechanics of Concrete 1986) were adapted to these materials. See Reyes (2004) for details.

The meso-scale approach was adopted for numerical modelling. As previously explained, this approach does not make any distinction between units and mortar, averaging the effect of the composite material through a fictitious continuous material. TPB fracture tests were performed following the RILEM 50-FMC (RILEM 50-FMC Committee Fracture Mechanics of Concrete 1986) to obtain the fracture energy of the brickwork masonry for three orientations of the joints $\left(0^{\circ}, 45^{\circ}\right.$ and $\left.90^{\circ}\right)$. Figure 9 shows the test arrangement for a masonry panel with the joints at $45^{\circ}$. The values of the longitudinal deformation modulus and traction strength were indirectly obtained from this test. Table 2 summarises the results.

\subsubsection{Mixed mode fracture tests}

The tests were carried out on the prismatic masonry panels described above, under TPB configuration. To acquire mixed mode loading conditions, the test was performed under nonsymmetric boundary, as shown in Fig. 8. Thirty-six masonry panels of two different sizes $(D=75 \mathrm{~mm}$ and $150 \mathrm{~mm})$ and several orientations of the joints $\left(0^{\circ}, \pm 30^{\circ}, \pm 45^{\circ}, \pm 60^{\circ}\right.$ and 


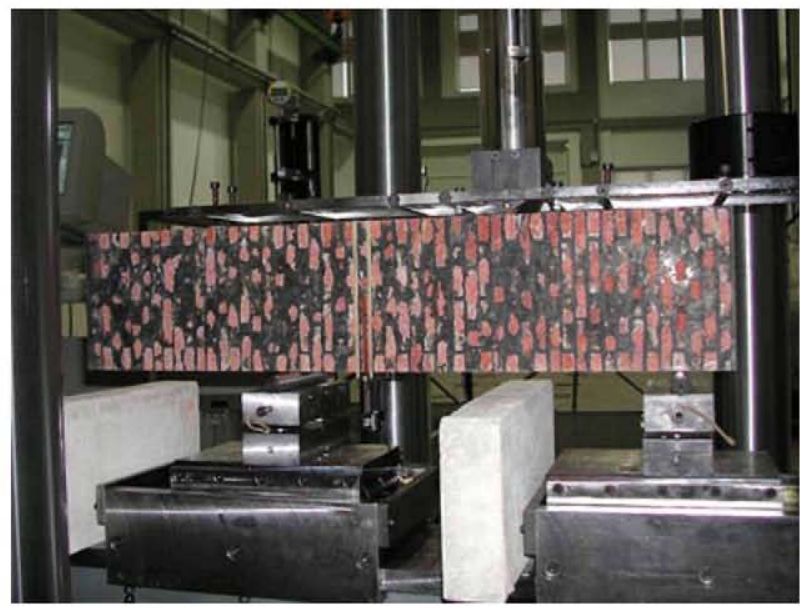

Fig. 10 Large size $(D=150 \mathrm{~mm}) \mathrm{TPB}$ specimen, with the bed joints at $90^{\circ}$, during testing

$90^{\circ}$ ), were tested. Only small specimens with the orientation of the joints at $\pm 30^{\circ}$ and $\pm 60^{\circ}$ were analysed. Figure 10 shows a large size specimen during mixed mode testing.

The masonry beams rested on two rigid steel cylinders laid on two ground supports, which allowed free rotation out of the plane of the beam and guarantee negligible friction rolling in the longitudinal direction of the beam. During the test, applied load, load-point displacement and crack mouth opening displacement (CMOD) were continuously recorded. The tests were performed in CMOD control, at a rate of $0.04 \mathrm{~mm} / \mathrm{min}$. Further details may be found elsewhere (Reyes 2004).

\section{Results and discussion}

\subsection{Numerical prediction of the experimental mixed mode fracture results}

The presented numerical procedure is used to reproduce the experimental results. The crack path was calculated by means of LEFM and incorporated into the finite element mesh. Figure 11 shows the experimental and the numerical prediction of the crack paths for the two sizes of specimens, and the four orientations of the bed joints. The numerical prediction is a sufficiently accurate approximation of the crack path, valid for the four orientations of the bed joints. In this sense, it is noticeable that masonry exhibits a wider experimental scatter than other quasibrittle materials such as mortar and concrete. The use of a single numerical crack path, and then only one finite element mesh, leads to a less time consuming calculation procedure. Figure 12 shows a finite element mesh used to study the mixed mode fracture of the brickwork masonry panels.

In the crack path were incorporated the interface elements with the cohesive crack model. Table 2 shows the mode I fracture properties of the material, measured with standardized methods. The mode II fracture parameters were estimated in accordance with Reyes (2004), Cervenka (1994), Table 3 shows these parameters. According to Gálvez et al. (2002a), Cervenka (1994) the friction angle and the dilatancy angle, were adopted: $\phi_{f}=0.5$ and $\phi_{d}=0.3$ rad. 

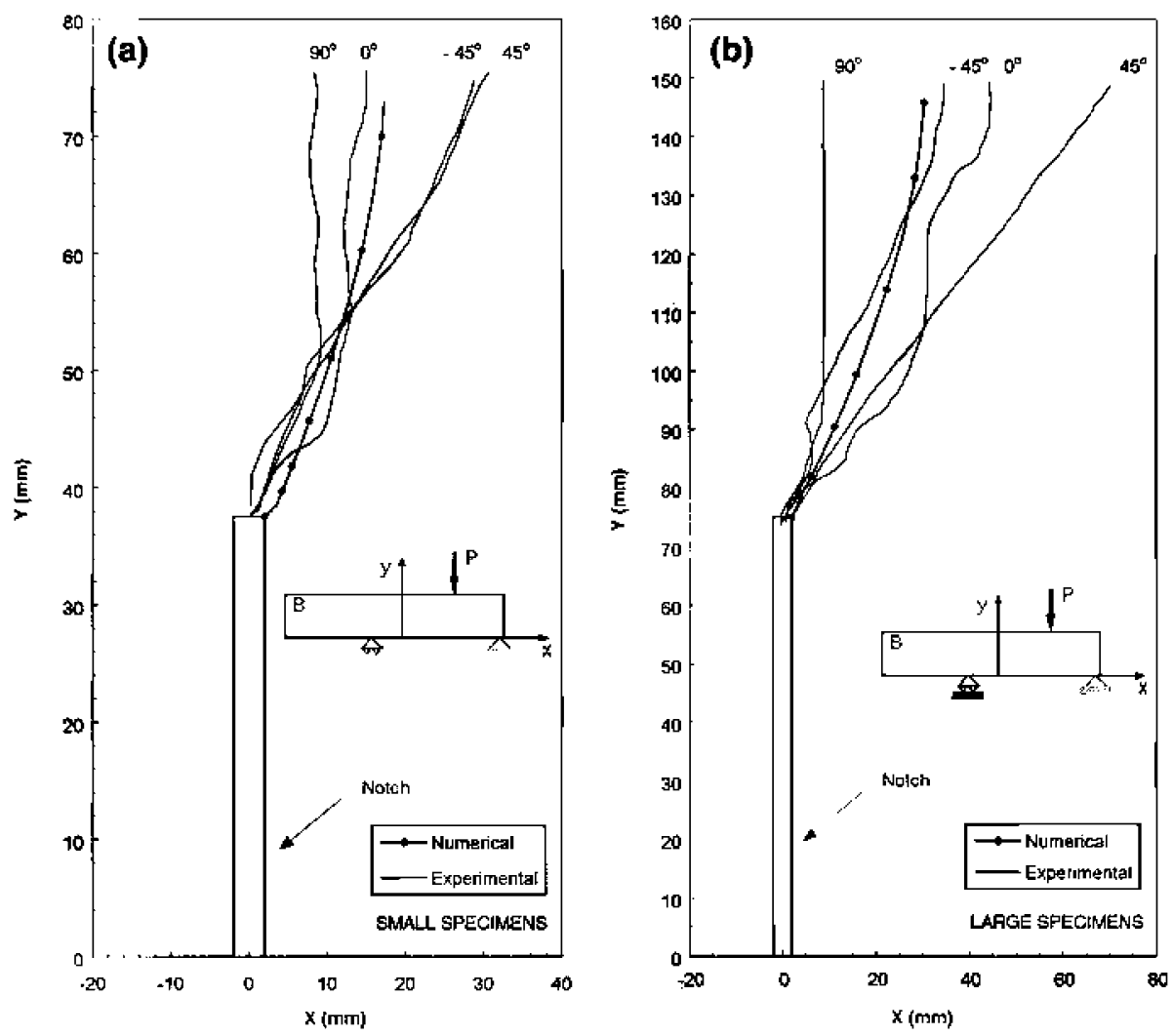

Fig. 11 Mean experimental (from three specimens) and numerical prediction of the crack path: (a) small specimens $(D=75 \mathrm{~mm})$, (b) large specimens $(D=150 \mathrm{~mm})$

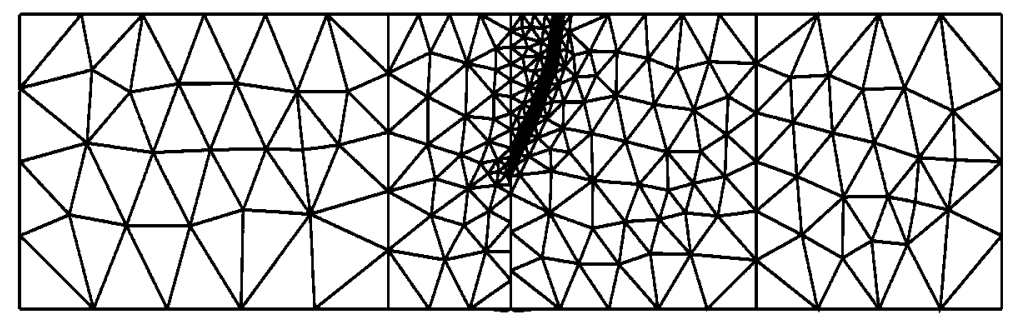

Fig. 12 Finite element mesh for the small size $(D=75 \mathrm{~mm})$ test modelling

Table 3 Estimated mode IIa fracture parameters for brick masonry (Reyes et al. 2004; Reyes 2004)

\begin{tabular}{lll}
\hline Orientation & $G_{F}^{I I a}(\mathrm{~N} / \mathrm{m})$ & $\mathrm{c}\left(\mathrm{N} / \mathrm{mm}^{2}\right)$ \\
\hline Horizontal & 77.6 & 6 \\
$45^{\circ}$ & 65.8 & 5 \\
Vertical & 55 & 4 \\
\hline
\end{tabular}



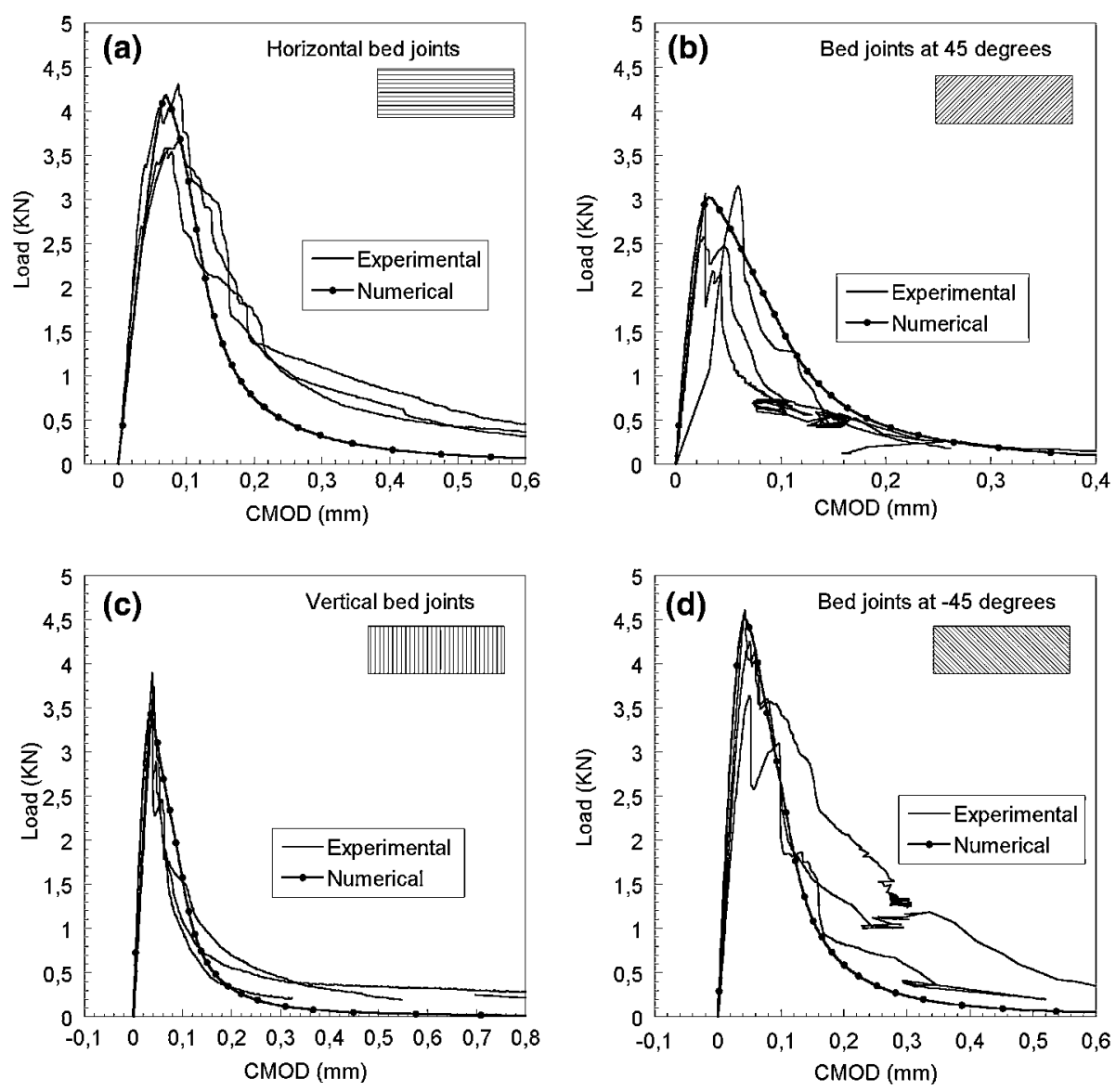

Fig. 13 Experimental records and numerical prediction of load $\mathbf{P}$ versus $C$ MOD for large size TPB specimens $\left(D=150 \mathrm{~mm}\right.$ ) with the bed joints at: (a) $0^{\circ}$, (b) $45^{\circ}$, (c) $90^{\circ}$, and (d) $-45^{\circ}$

Figures 13 and 14 compare the experimental records load versus CMOD and load versus displacement of the application point of the load for the large size specimens $(\mathrm{D}=$ $150 \mathrm{~mm}$ ) and different orientations of bed joints, with the numerical prediction. In all cases the experimental records show stable tests with the entire post-peak descending branch curve. Numerical model properly predicts the peak load and fit quite well the entire behaviour of the experimental records.

Figures 15 and 16 also show analogous comparison for the small size specimens $(D=$ $75 \mathrm{~mm}$ ). With this smaller size of specimens the numerical prediction is not so good that with largest specimens, especially with horizontal bed joints. This aspect is more relevant in the curves load versus load-point displacement, where the numerical model predicts a snap-back higher than the experimental ones.

The smallest specimens $(D=75 \mathrm{~mm})$ the largest experimental scatter band. On the smallest specimens, the ligament of the notched bending beam only includes three brick layers, then the relative size of the individual components (bricks, mortar and joins) is larger in comparison with the specimen size, causing a larger scatter in the failure behaviour. 

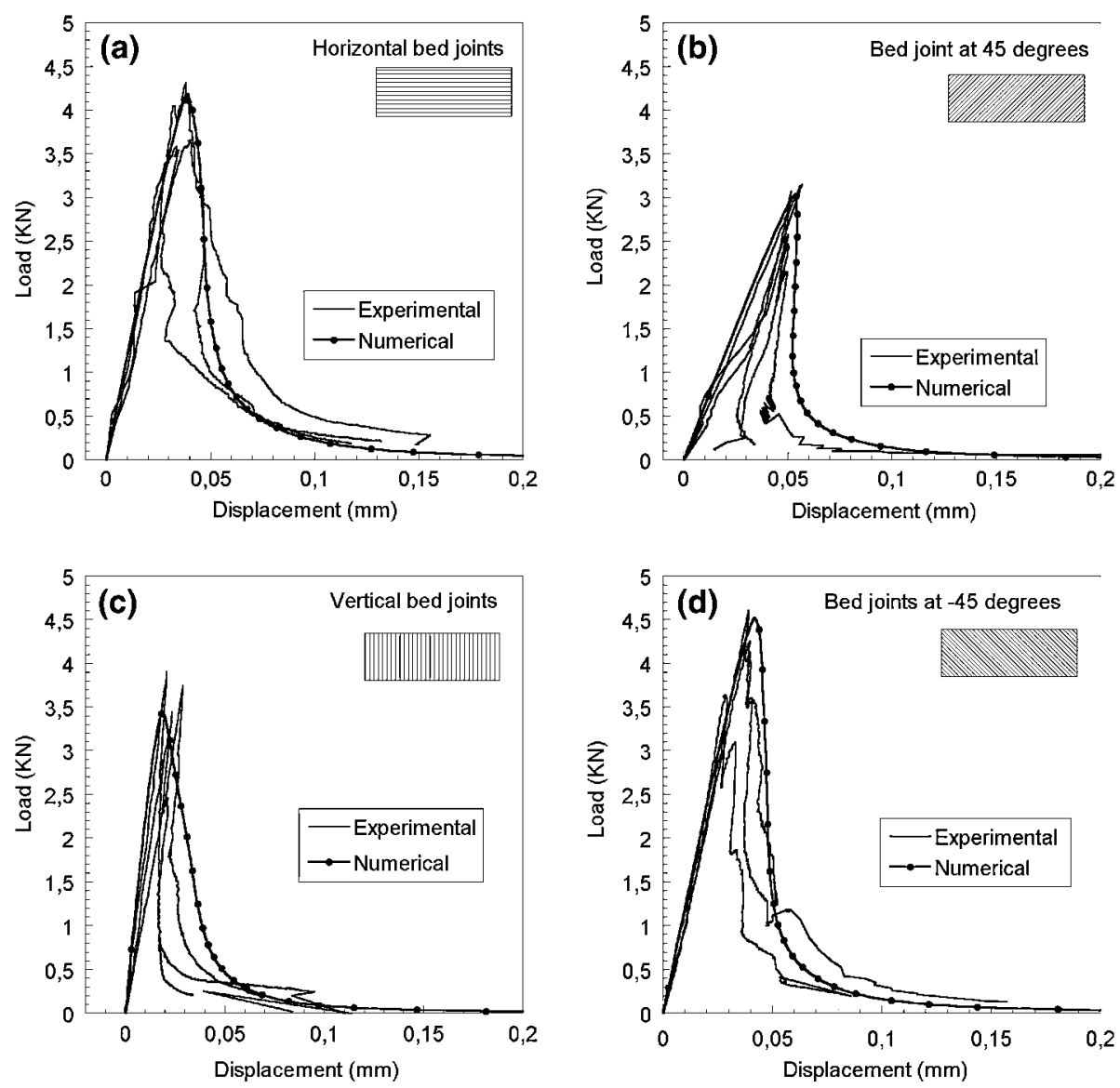

Fig. 14 Experimental records and numerical prediction of load $\mathrm{P}$ versus load point displacement for large size TPB specimens $(D=150 \mathrm{~mm})$ with the bed joints at: (a) $0^{\circ}$, (b) $45^{\circ}$, (c) $90^{\circ}$, and (d) $-45^{\circ}$

Cohesive crack model predicts the size effect and the snap-back behaviour of the load versus load point displacement. The experimental snap-back behaviour of these curves is more accentuated on the smallest specimens, but is overestimated by the numerical model. This may be caused because the numerical model averaging the fracture behaviour on the fracture process zone while the real material includes weaker individual mechanisms, like interface brick-mortar, which may soften the snap-back behaviour. In this sense the snap-back prediction of the largest specimens is much better, and it confirms that the averaging is better when the relative size of the beam, in comparison with the individual components, is larger.

\subsection{Numerical simulation with recorded experimental trajectories}

A key point of the model is that the crack path is provided by the LEFM prediction. This hypothesis has been successful with concrete (Gálvez et al. 2002a,b) and other quasi-brittle materials. As shown above, the hypothesis also works with the tested masonry, reaching an accurate fit with experimental results (curves load versus point load displacement and load 

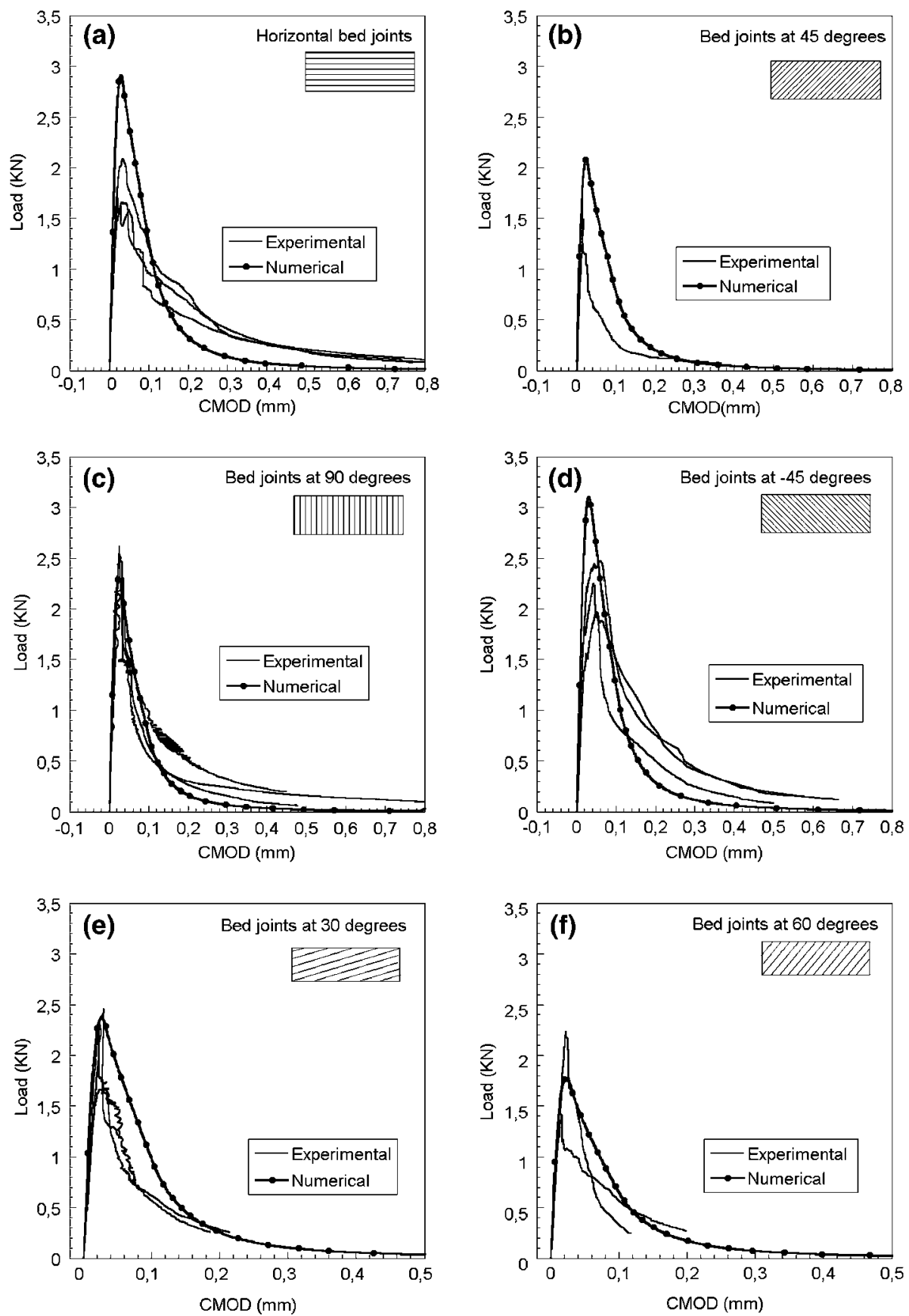

Fig. 15 Experimental records and numerical prediction of load P versus CMOD for small size TPB specimens $\left(D=75 \mathrm{~mm}\right.$ ) with the bed joints at: (a) $0^{\circ}$, (b) $45^{\circ}$, (c) $90^{\circ}$, (d) $-45^{\circ}$, (e) $30^{\circ}$, and (f) $60^{\circ}$ 

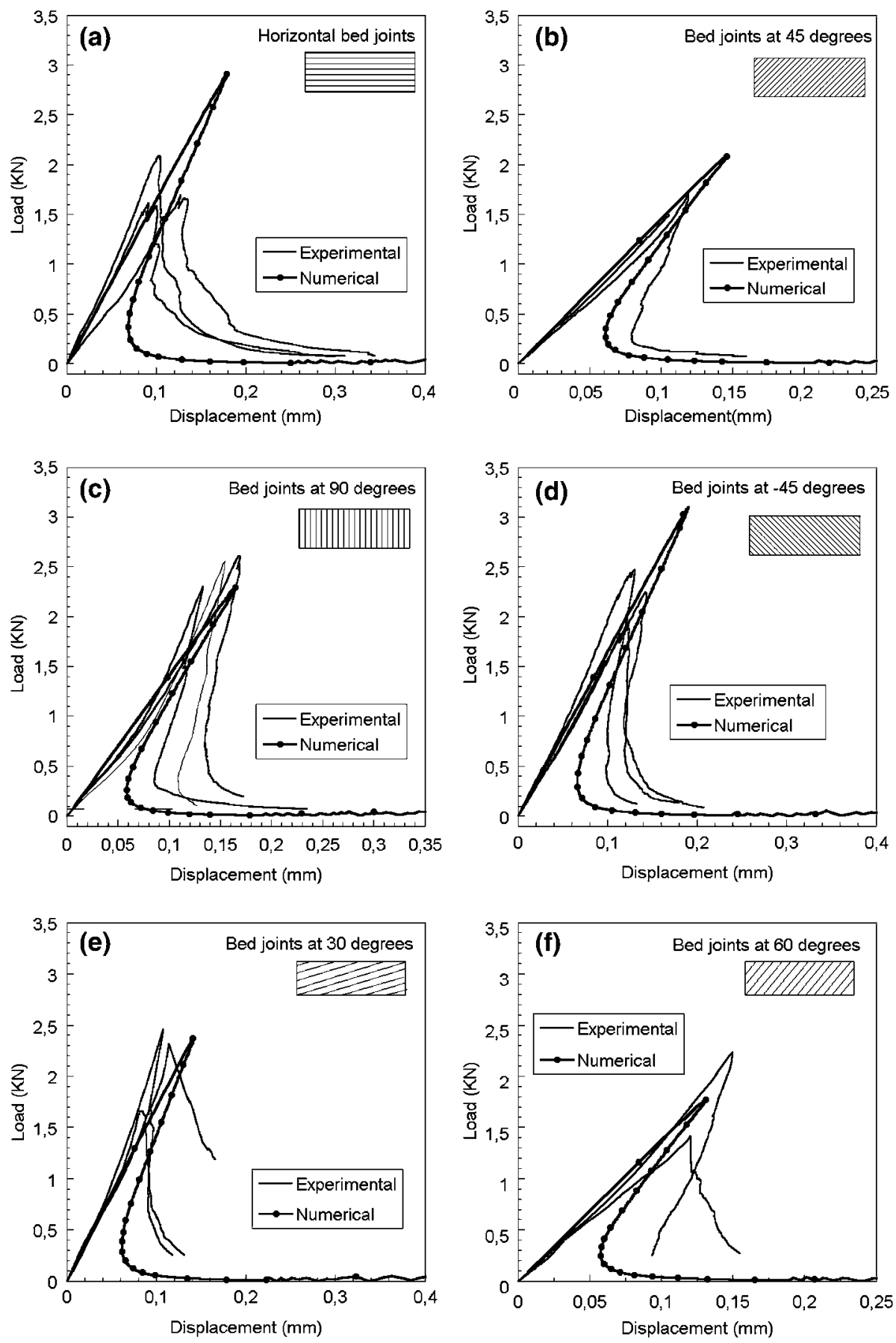

Fig. 16 Experimental records and numerical prediction of load $\mathrm{P}$ versus load point displacement for small size TPB specimens $(D=75 \mathrm{~mm})$ with the bed joints at: (a) $0^{\circ}$, (b) $45^{\circ}$, (c) $90^{\circ}$, (d) $-45^{\circ}$, (e) degrees, and (f) $60^{\circ}$ 

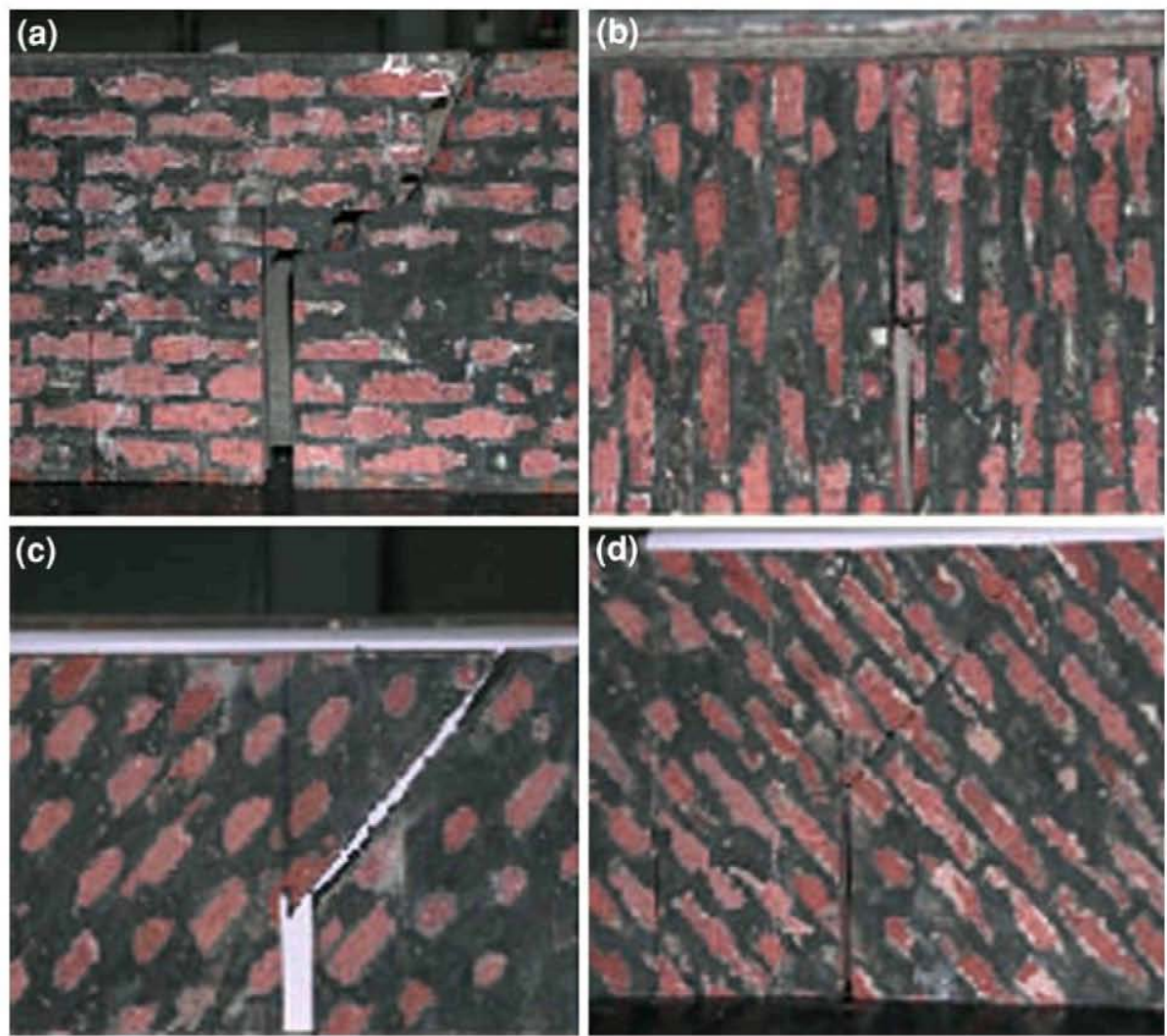

Fig. 17 Cracks on the TPB large specimens $(D=150 \mathrm{~mm})$ after testing with the bed joints at: (a) 0, (b) 90 , (c) 45 , and (d) $-45^{\circ}$

versus $\mathrm{CMOD}$ ), though the crack path prediction can be less accurate when the crack grows by the interface mortar-brick, usually the weakest part of the masonry.

Figure 17 shows photos of the crack paths of the testing specimens, revealing quite different crack paths depending on the orientation of the brick layers. Real experimental trajectories, instead of LEFM prediction, have been inserted in the finite element mesh to simulate the fracture behaviour of the specimens. Figure 18 shows the load versus CMOD and Fig. 19 the load versus load point displacement, for some of the tested specimens which worse numerical prediction showed before. The prediction of the experimental results is more accurate, especially the peak load and the snap-back prediction.

These results help to assess the balance between accuracy and simplicity of the modelling. The proposed model, with the LEFM forecast, provides a good prediction of the experimental results and only needs the mechanical characterisation of the masonry. The approach is recommendable for large (in comparison with individual components) structural elements, providing a helpful tool in studying the macrocracking of masonry. Evidently, a more accurate prediction is reached if the real crack path is used, though this is not a predictive approach (as the crack preexists in the structure) and supplementary meshing work is needed. While this approach is commendable for testing smaller panels, it is not acceptable for engineering 

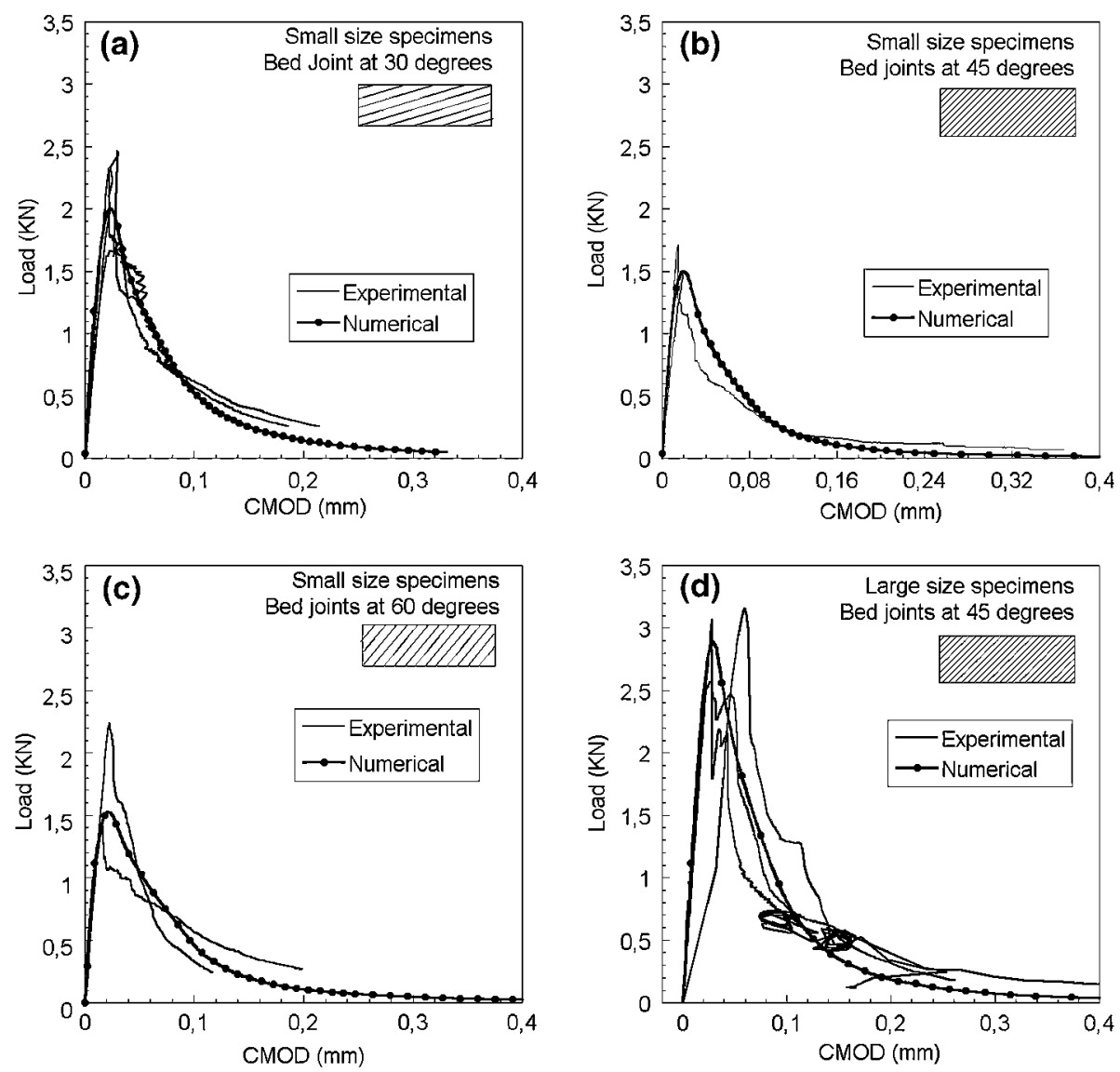

Fig. 18 Experimental records and numerical prediction of load P versus CMOD for the simulation with recorded crack path. Small size specimens $(D=75 \mathrm{~mm})$ with bed joints at: (a) $30^{\circ},(\mathbf{b}) 45^{\circ}$, (c) $60^{\circ}$; and (d) large size ( $D=150 \mathrm{~mm}$ ) with bed joints at $45^{\circ}$

purposes. In any case, for medium or small masonry panels, a more detailed analysis of brick and mortar interaction would be required.

\section{Cohesive stress along the crack path}

Figure 20a shows six selected points on the crack path for evaluating the normal stress when the crack is growing. Figure $20 \mathrm{~b}$ and $\mathrm{c}$ shows the normal stress on these points under peak load, for the specimens with horizontal and vertical bed joints and the two specimen sizes. Figures $20 \mathrm{~d}$ and $20 \mathrm{e}$ show analogous results when the peak load is exceeded and the load rate is the $70 \%$ of the peak load on the descending branch. On these figures, the normal stress to crack faces, $\sigma$, is normalised by dividing it by the tensile strength, $f_{t 0}$, and the crack opening $\omega$ is normalised by dividing it by the critical crack opening $\omega_{c h}$, where $\omega_{c h}=G_{F} / f_{t 0}$.

At peak load (Fig. 20b and c), the normal stress of the first five points (A-E) is on the first part of the bilinear softening function (except for point $\mathrm{E}$ ' in small specimens with horizontal 

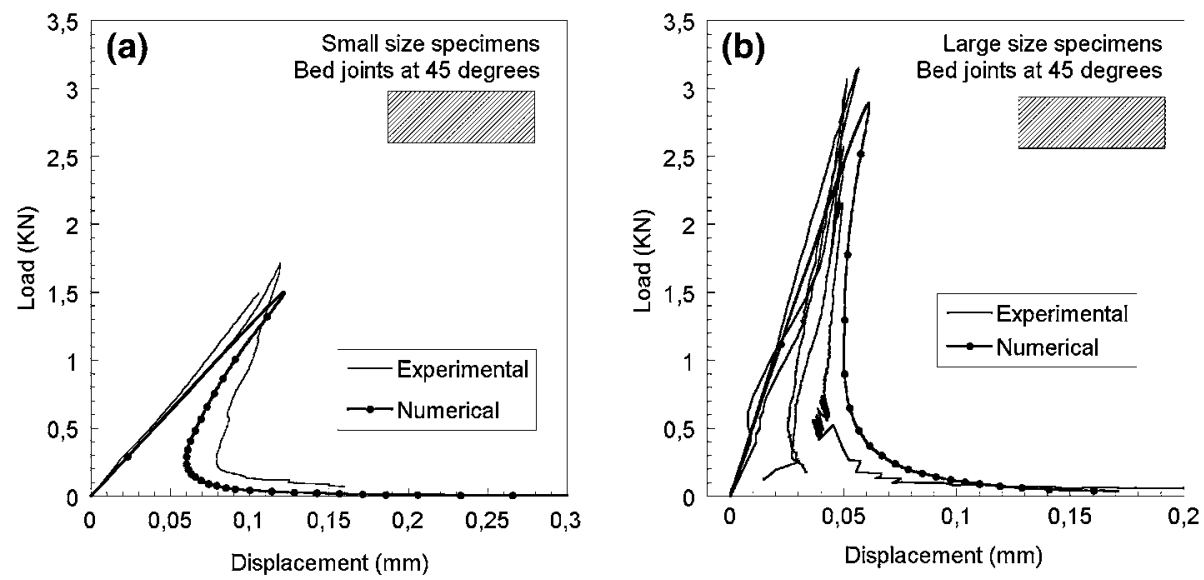

Fig. 19 Experimental records and numerical prediction of load $\mathrm{P}$ versus load point displacement for the simulation with recorded crack path: (a) small size specimens $(D=75 \mathrm{~mm})$ with bed joints at $45^{\circ}$, and (b) large size $(D=150 \mathrm{~mm})$ with bed joints at $45^{\circ}$

(a)

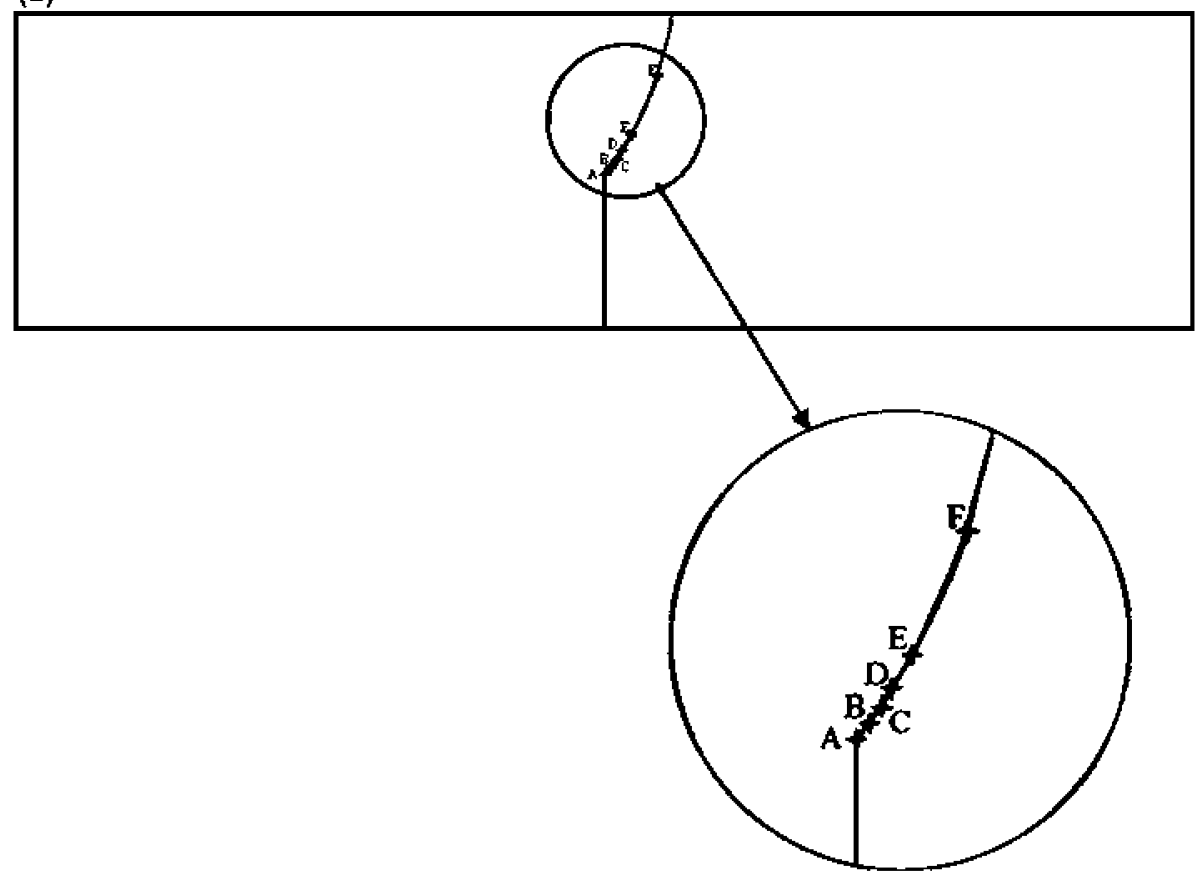

Fig. 20 Tensile cohesive stress along the crack path: (a) selected points on the crack path, (b) horizontal bed joints specimens under peak load, (c) vertical bed joints specimens under peak load, (d) horizontal bed joints specimens under post peak loading (70\%), (e) vertical bed joints specimens under post peak loading $(70 \%)$, (f) normalized load $P$-displacement curve 

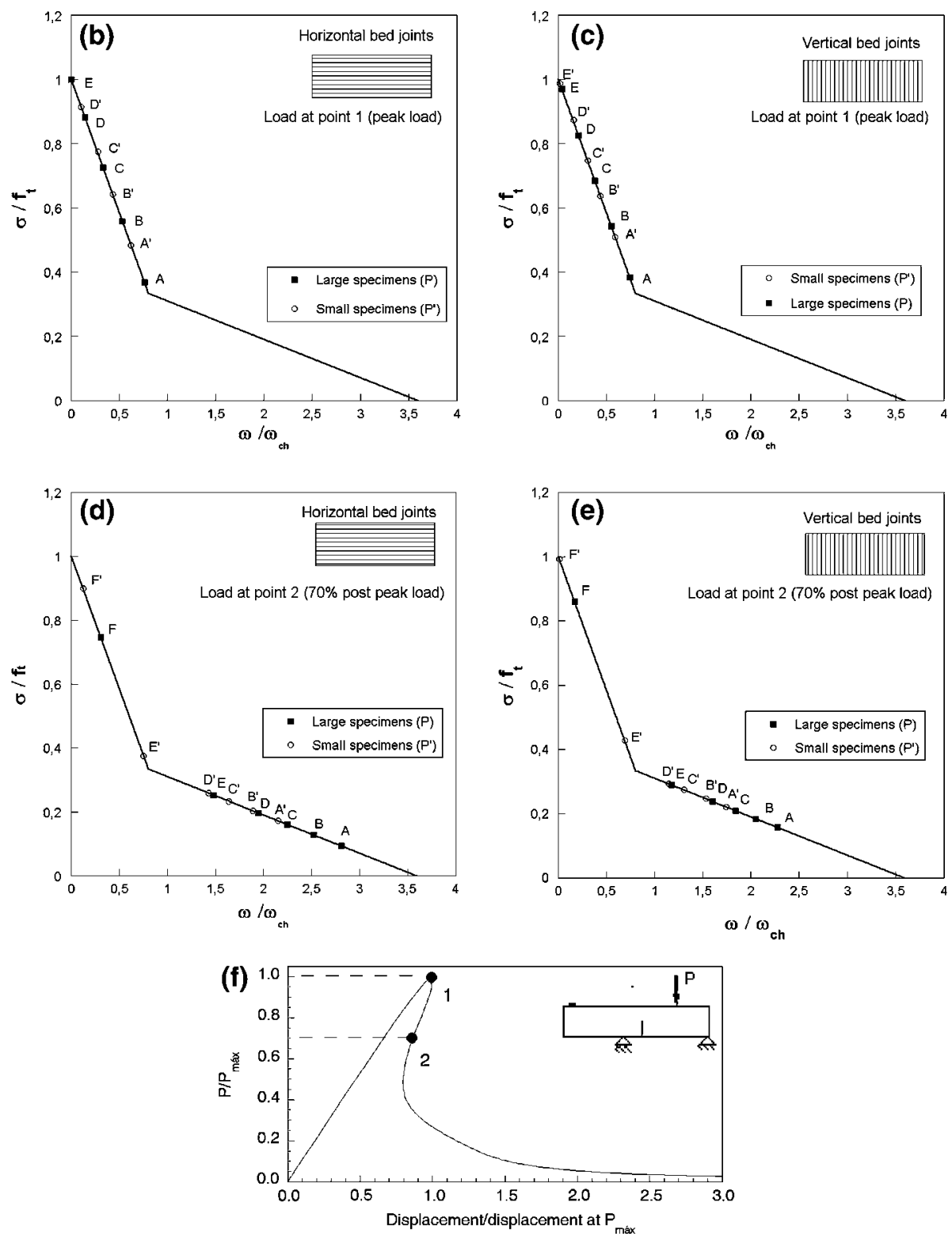

Fig. 20 continued

bed joints). In this case the cohesive zone, named fracture process zone (FPZ) by some authors, extends to approximately $30 \%$ of the final crack length. The point $\mathrm{F}$ is still under elastic regime. This result corroborates that the peak load is governed by tensile strength and the initial part of the softening curve.

When the peak load is exceeded, and the load rate is $70 \%$ of peak load on the descending branch (Fig. 20d and e), the normal stress of the five first points (A-E) in large size specimens, and four first points $\left(\mathrm{A}^{\prime}-\mathrm{D}^{\prime}\right)$ in small size specimens, is on the second part of the softening 
function. For this loading rate, the cohesive zone extends approximately up to $65 \%$ of total crack length (vertical bed joints) or even $70 \%$ (horizontal bed joints). This result seems to suggest that the post peak load behaviour is determined by the total shape of softening curves, and especially by the ending part of the curve.

For the two loading states, and the two orientations selected, the large size specimens possess the more advanced position in the softening function.

\section{Summary and conclusions}

A cohesive crack numerical model for mixed mode fracture of masonry has been proposed. The model is an extension to anisotropic materials of the cohesive model developed by Gálvez et al. (2002a,b) for mixed mode fracture of concrete (isotropic material). The numerical procedure uses LEFM crack prediction, takes into account the anisotropy of the material, and has been implemented in a commercial finite element code by means of a user subroutine.

A series of mixed mode fracture tests on small masonry panels under non-symmetric TPB were performed. While the aim of the experimental work was to check the model and capture the essentials of the masonry fracture, its objective was not to be a small scale modelling of real masonry walls. Specimens with different inclinations of the bed joints and two similar (ratio 2) sizes were tested. The interface brick-mortar was shown as the weakest part of the masonry. The highest load failure was reached on the specimens whose orientation of the brick layers was so that the crack cut bricks and joins. The lowest load failure was reached when the crack run by the interface brick-mortar. Extension of these results to full-scale masonry structures requires additional work.

The numerical model correctly predicts the experimental results. Numerical simulation based on the LEFM crack path prediction provides a good fit of the load versus CMOD and load versus load point displacement experimental curves. The larger specimens $(D=$ $150 \mathrm{~mm}$ ) provide the most consistent agreement between numerical prediction and experimental results. If the real crack path is incorporated into the finite element mesh, instead of the LEFM prediction, the numerical prediction is better, especially on the smallest specimens $(D=75 \mathrm{~mm})$. Such an approach needs additional meshing work and requires that the researcher be familiar with the path of the real crack, i.e. that it provides a post cracking analysis.

The proposed model procedure reaches a balance between accuracy and simplicity, and provides a helpful tool in predicting the fracture of large masonry structural elements when a single macro-crack, or finite number of them, is the main failure mechanism. The presented model does not include distributed cracking or damage in the structure and applies in the case of a macro-crack occurring.

The presented numerical model and the experimental results emphasise that the cohesive crack models, taking into account the anisotropy of the masonry, are promising tools in the simulation of the mixed mode fracture of the masonry in large structural elements. For engineering purposes, the averaging of the masonry properties provides rough but sufficiently precise data for cohesive modelling. For small masonry elements, a more detailed analysis of fracture micro-mechanisms, especially interface brick-mortar interaction, is required.

Acknowledgements The authors gratefully acknowledge the financial support for the research provided by the Spanish Ministerio de Educación y Cultura under grant BIA-2005-09250-CO3-02 and by the Ministerio de Fomento under grants MFOM-2004/9 and MFOM-01/07. In addition, they also thank the Junta de Com- 
unidades de Castilla La Mancha and the Universidad de Castilla La Mancha under grant PAI069-0071-9403 for the complementary financial support received.

\section{References}

Abboud BE, Hamid HG (1990) Small-scale modeling of concrete block masonry structures. ACI Struct J $87(2): 145-155$

Abdoud BE, Hamid AA, Harris HG (1996) Flexural behavior of reinforced concrete masonry walls under out of plane monotonic loads. ACI Struct J 93(3):327-335

Abdou L, Saada RM, Meftah F, Mebarki A (2006) Experimental investigations of the joint-mortar behavior. Mechanics 33:370-384

Alfaiate J, Almeida JR (2000) Discrete cracking of masonry walls. In: European congress on computational methods in applied sciences and engineering, ECCOMAS 2000, $15 \mathrm{pp}$

Alshebani M, Sinha S (1999) Stress-strain characteristics of brick masonry under uniaxial cyclic loading. J Struct Eng 125(6):600-604. doi:10.1061/(ASCE)0733-9445(1999)125:6(600)

Anthoine A (1995) Derivation of the in-plane elastic characteristics of masonry through homogenization theory. Int J Solids Struct 32(2):137-163. doi:10.1016/0020-7683(94)00140-R

Bažant ZP, Pfeiffer PA (1986) Shear fracture tests of concrete. Mater Struct 19:111-121. doi:10.1007/ BF02481755

Bažant ZP, Planas J (1998) Fracture and size effect in concrete and other quasibrittle materials. CRC Press, New York

Bocca P, Carpinteri A, Valente V (1989) Fracture analysis of brick masonry: Size effects and snap-back analysis. Mater Struct 27:99-105

Bernardini A, Modena C, Valluzi MR (1998) Load transfer mechanisms in masonry: friction along a crack within a brick. Mater Struct 31:42-48. doi:10.1007/BF02486413

Bosiljkov V, Zarnic R, Kralj B, Pande GN (1998) Experimentally-based computational modelling of masonry. In: Pande GN, Middleton J, Kraj B (eds) Computer methods in structural masonry-4. E\&FN Spon, New York pp 103-110

Bosiljkov V, Zarnic R, Bosiljkov VB (2000) Shear tests of the URM panels made from different types of mortar: an experimental study. In: Adell JM (ed) 12th brick/block masonry Conf. (IBMAC), vol 1, pp 303-307

Broek D (1986) Elementary engineering fracture mechanics. Martinus Nijhoff Pub, The Netherlands, pp 374-380

Carol I, Prat P, López M (1997) Normal/shear cracking model: application to discrete crack analysis. J Eng Mech 123:765-773. doi:10.1061/(ASCE)0733-9399(1997)123:8(765)

Carpinteri A (1994) Cracking of strain-softening materials. In: Aliabadi M.H. et al (ed) Static and dynamic fracture mechanics. Comp Mech Pub, Southampton pp 311-365

Carpinteri A, Chiaia B, Bocca P (1997) Size dependence of strength and fracture properties of brickwork masonry walls. J Eng Mech 123(8):816-822. doi:10.1061/(ASCE)0733-9399(1997)123:8(816)

Cecchi A, Di Marco R (2002) Homogenized strategy toward constitutive identification of masonry. J Eng Mech 128:688-697. doi:10.1061/(ASCE)0733-9399(2002)128:6(688)

Cendón DA (2002) Study of the mixed mode fracture of concrete and mortar. Ph.D. Thesis, Universidad Politécnica Madrid, Madrid (in Spanish)

Cendón DA, Gálvez JC, Elices M, Planas J (2000) Modelling the fracture of concrete under mixed loading. Int J Fract 103:293-310. doi:10.1023/A:1007687025575

Cervenka J (1994) Discrete crack modelling in concrete structures. Ph. D. Thesis, University of Colorado

Cormeau AF, Shrive NG (1996a) Development of a fracture mechanics approach for masonry. In: Bailly ME, Spodler DE (eds) 7th North American masonry conference, pp 379-388

Cormeau AF, Shrive N (1996b) Fracture mechanics and future strength design of masonry. In: Bailly ME, Spodler DE (eds) 7th North American masonry conference, pp 477-488

Dhanasekar M, Kleeman P, Page AW (1985a) Biaxial stress-strain relations for brick masonry. J Struct Eng 3(5):1085-1100

Dhanasekar M, Page AW, Kleeman PW (1985b) The failure of brick masonry under biaxial stresses. Proc Inst Civ Eng 79(2):295-313

di Prisco M, Ferrara L, Meftah F, Pamin J, de Borst R, Mazars J et al (2000) Mixed mode fracture in plain and reinforced concrete: some results on benchmark tests. Int J Fract 103:127-1489. doi:10.1023/A: 1007613001402

El-Metwally SE, Ashour AF, Chen WF (1991) Behaviour and strength of concrete masonry walls. ACI Struct J $88(1): 42-48$ 
Erdogan F, Sih GC (1963) On the crack extension in plates under plane loading and transverse shear. J Basic Eng 85:519-527

Gálvez JC, Elices M, Guinea GV, Planas J (1996) Crack trajectories under mixed mode and non-proportional loading. Int J Fract 81:171-193. doi:10.1007/BF00033181

Gálvez JC, Elices M, Guinea GV, Planas J (1998) Mixed mode fracture under propotional and nonproportional loading. Int J Fract 94:267-284. doi:10.1023/A:1007578814070

Gálvez JC, Reyes E, Casati MJ (2000) Brickwork masonry failure under tensile/shear loading. Mason Int 9: $184-191$

Gálvez JC, Cervenka J, Saouma V, Cendón DA (2002a) A discrete crack approach to normal/shear cracking of concrete. Cement Concr Res 32:1567-1585. doi:10.1016/S0008-8846(02)00825-6

Gálvez JC, Cendón DA, Planas J (2002b) Influence of shear parameters on mixed-mode fracture of concrete. Int J Fract 118:163-189. doi:10.1023/A:1022883132117

Giambanco G, Rizzo S, Spallino R (2001) Numerical analysis of masonry structures via interface models. Comput Methods Appl Mech Eng 190:6493-6511. doi:10.1016/S0045-7825(01)00225-0

Grimm CT (1988) Masonry cracks: a review of literature. Masonry: materials, design, construction and maintenance. In: Harris HA (ed) ASTM STP 992 American Society for Testing and Materials, Philadelphia, pp 257-280

Guinea GV, Planas J, Elices M (1994) Correlation between the softening and the size effect curves. In: Mihashi M (ed) et al Size effect in concrete structures. E\&F Spoon, London pp 233-244

Guinea GV, Elices M, Planas J (1997) On the initial shape of the softening function of cohesive materials. Int J Fract 87:139-149. doi:10.1023/A:1007416926604

Guinea GV, Hussein G, Elices M, Planas J (2000) Micromechanical modelling of brick-masonry fracture. Cement Concr Res 30:731-737. doi:10.1016/S0008-8846(00)00228-3

Hillerborg A, Modeer M, Petersson P (1976) Analysis of crack formation and crack growth in concrete by means of fracture mechanics and finite elements. Cement Concr Res 6:773-782. doi:10.1016/ 0008-8846(76)90007-7

Jenq Y, Shah SP (1988) Mixed-mode fracture of concrete. Int J Fract 38: 123-142

Jukes P, Riddintong JR (2001) The failure of brick triplet test specimens. Mason Int 15(1): 30-33

Khalaf FM, Hendry AW, Fairbairn DR (1994) Study of the compressive strength of blockwork masonry. ACI Struct J 91(4): 367-375

Lourenço PJ (1996) Computational strategies for masonry structures. Ph.D. Thesis, Delft, The Netherlands

Lourenço PB, Rots J (1993) On the use of micromodels for the analysis of masonry shear walls. In: Pande GN, Middleton J (eds) Computer methods in structural masonry-2. Swansea, pp 14-26

Lourenço PB, Ramos L (2004) Characterization of cyclic behavior of dry masonry joints. J Struct Eng 130:779786. doi:10.1061/(ASCE)0733-9445(2004)130:5(779)

Lourenço PJ, Rots J, Blaauwendraad J (1998) Continuum model for masonry: parameter estimation and validation. J Struct Eng 124(6):642-652. doi:10.1061/(ASCE)0733-9445(1998)124:6(642)

Massart TJ, Peerlings RHJ, Geers MGD, Gottcheiner S (2005) Mesoscopic modeling of failure in brick masonry accounting for three-dimensional effects. Eng Fract Mech 72:1238-1253. doi:10.1016/j.engfracmech. 2004.09.007

Milani G, Lourenço PB, Tralli A (2006) Homogenised limit analysis of masonry walls, Part I: Failure surfaces. Comput Struc 84:166-180. doi:10.1016/j.compstruc.2005.09.005

Mojsilovic N, Marti P (1997) Strength of masonry subjected to combined actions. ACI Struct J 94(6):633-642

Molnar M (2002) Shear and horizontal tension behavior of masonry model development and verification. Mason Int 15(2):53-58

Naraine K, Sinha N (1991) Model for cyclic compressive behavior of brick masonry.. ACI Struct J 88(5):603609

Naraine K, Sinha S (1992) Stress-strain for brick masonry in biaxial compression. J Struct Eng 118(6):14511461. doi:10.1061/(ASCE)0733-9445(1992)118:6(1451)

Page AW (1978) Finite element model for masonry. J Struct Div 104(8):1267-1285

Page AW (1981) The biaxial compressive strength of brick masonry. Proc Inst Civ Eng 71(2):893-906

Page AW (1983) The strength of brick masonry under biaxial tension-compression. Int J Mason Constr 3: 26-31

Papa E (1996) A unilateral damage model for masonry based on homogenization procedure. Mech CohesiveFrictional Mater 1:349-366. doi:10.1002/(SICI) 1099-1484(199610)1:4<349::AID-CFM18>3.0.CO;2$\mathrm{M}$

Papa E, Nappi A (1997) Numerical modeling of masonry: A material model accounting for damage defects and plastic strains. Appl Math Model 21:319-335. doi:10.1016/S0307-904X(97)00011-5

Petersson PE (1981) Crack growth and development of fracture zones in plain concrete and similar materials. Report TVBM-1006, Div. of Building Materials, Lund Institute of Technolgy, Sweeden 
Pietruszczak S, Ushaksaraei R (2003) Description of inelastic behavior of structural masonry. Int J Solids Struct 40:4003-4019. doi:10.1016/S0020-7683(03)00174-4

Planas J, Guinea GV, Elices M (1995) Rupture modulus and fracture properties of concrete. In: Wittmann FH (ed) Fracture mechanics of concrete structures. Aedificatio Publishers, Freiburg pp 95-110

Rahman MA, Anand SC (1994) Empirical Mohr-Coulomb failure criterion for concrete block-mortar joints. J Struct Eng 120:2408-2422. doi:10.1061/(ASCE)0733-9445(1994)120:8(2408)

Reyes E (2004) Fracture of the brickwork masonry under tensile/shear loading. Ph.D. Thesis (in Spanish), Ciudad Real, Spain

Reyes E, Casati MJ, Gálvez JC (2004) Normal/shear cracking of brickwork masonry. In: Li V et al (eds) Fracture mechanics of concrete structures, pp $415-422$

Riddington JR, Naom NF (1994) Finite element prediction of masonry compressive strength. Comput Struc 52(1):113-119. doi:10.1016/0045-7949(94)90261-5

RILEM50-FMC Committee Fracture Mechanics of Concrete (1986) Determination of the fracture energy of mortar and concrete by means of three-point bend tests on notched beams. Mater Construct 18:285-290

Rots JG (1991) Numerical simulation of cracking in structural masonry. HERON 36:49-63

Salerno G, Bilotta A, Porco F (2001) A finite element with micro-scale effects for the linear analysis of masonry brickwork. Comput Methods Appl Mech Eng 190:4365-4378. doi:10.1016/S0045-7825(01)00165-7

Steward MG, Lawrence S (2002) Structural reliability of masonry walls in flexure. Masonry Int 15(2):48-52

Uva G, Salerno G (2006) Towards a multiscale analysis of periodic masonry brickwork: a FEM algorithm with damage and friction. Int J Solids Struct 43:3739-3769. doi:10.1016/j.ijsolstr.2005.10.004

van der Pluijm R (1997) Non linear behavior of masonry under tension. HERON 42(1):25-53

van der Pluijm R (1999) Out of plane bending of masonry behaviour and strength. Ph.D. Thesis, Delft, The Netherlands

Wawryzynek P, Ingraffea A (1994) FRANC2D: a two-dimensional crack propagation simulator, version 2.7

Zucchini A, Lorento PB (2002) A micro-mechanical model for the homogenization of masonry. Int J Solids Struct 39:3233-3255. doi:10.1016/S0020-7683(02)00230-5 